\title{
Lipid conformation in model membranes and biological membranes
}

\author{
JOACHIM SEELIG AND ANNA SEELIG
}

Department of Biophysical Chemistry, Biocenter of the University of Basel, Klingelbergstrasse 70, 4056 Basel, Switzerland

II. SPECTROSCOPIC METHODS FOR MEMBRANE STUDIES

(I) Deuterium magnetic resonance 20

(2) Neutron diffraction 24

(3) Phosphorus-31 nuclear magnetic resonance 25

III. STRUCTURE OF THE HYDROCARBON REGION

(I) Bent and straight hydrocarbon chains 27

(2) Order profiles of model membranes and biological membranes 33

(3) Phospholipid dynamics and membrane fluidity 40

IV. LIPID-PROTEIN INTERACTION

V. THE POLAR HEAD GROUPS: IONIC INTERACTIONS

VI. ACKNOWLEDGEMENTS

\section{INTRODUCTION}

Protein molecules in solution or in protein crystals are characterized by rather well-defined structures in which $\alpha$-helical regions, $\beta$-pleated sheets, etc., are the key features. Likewise, the double helix of nucleic acids has almost become the trademark of molecular biology as such. By contrast, the structural analysis of lipids has progressed at a relatively slow pace. The early X-ray diffraction studies by V. Luzzati and others firmly established the fact that the lipids in biological membranes are predominantly organized in bilayer structures (Luzzati, 1968). V. Luzzati was also the first to emphasize the liquid-like conformation of 
the hydrocarbon chains, similar to that of a liquid paraffin, yet with the average orientation of the chains perpendicular to the lipid-water interface. This liquid-crystalline bilayer is generally observed in lipidwater systems at sufficiently high temperature and water content, as well as in intact biological membranes under physiological conditions (Luzzati \& Husson, I962; Luzzati, 1968; Tardieu, Luzzati \& Reman, 1973; Engelman, 1971; Shipley, 1973). In combination with thermodynamic and other spectroscopic observations these investigations culminated in the formulation of the fluid mosaic model of biological membranes (cf. Singer, 1971). However, within the limits of this model the exact nature of lipid conformation and dynamics was immaterial, the lipids were simply pictured as circles with two squiggly lines representing the polar head group and the fatty acyl chains, respectively. No attempt was made to incorporate the well-established chemical structure into this picture. Similarly, membrane proteins were visualized as smooth rotational ellipsoids disregarding the possibility that protruding amino acid side-chains and irregularities of the backbone folding may create a rather rugged protein surface.

In this article we draw attention to the significance of phospholipid conformation for the organization of biological membranes. Distinct conformational constraints are imposed on the phospholipid molecules, on the headgroups as well as on the fatty acyl chains. To represent the bilayer by a confusion of entangled lines is certainly an oversimplification. Many features of phospholipid conformation are qualitatively and quantitatively quite similar and are independent of the specific chemical nature of the phospholipid investigated. New methods have been designed and a wealth of experimental data has been accumulated during the last five years; the purpose of this review is then to summarize the more general features of lipid conformation which have emerged from these studies. Due to lack of space simple soap-like bilayers will not be included in this article.

\section{SPECTROSCOPIC METHODS FOR MEMBRANE STUdIES}

\section{Deuterium magnetic resonance}

By means of chemical synthesis or biochemical incorporation deuterium is introduced at a specific site of the phospholipid molecule, i.e. at the polar head group, the glycerol backbone or the fatty acyl chains. 
Virtually all segments of a phospholipid molecule are accessible by means of a suitable combination of both techniques. The selective replacement of ${ }^{1} \mathrm{H}$ by ${ }^{2} \mathrm{H}$ is not expected to perturb the natural arrangement of the molecule in the membrane, except, perhaps where specific hydrogen bonding is involved. The natural abundance of deuterium is low $(0.016 \%)$ and deuterium magnetic resonance has therefore the advantage over other types of $\mathrm{nmr}$ spectroscopy in that the deuterium $\mathrm{nmr}$ signal can be immediately assigned to the deuterium labelled site. At the same time the magnetic dipole moment of ${ }^{2} \mathrm{H}$ is a factor of $\sim 6$ smaller than that of ${ }^{1} \mathrm{H}$ and interactions with neighbouring protons have little effect on the spectrum. The ${ }^{2} \mathrm{H}-\mathrm{nmr}$ spectrum is therefore easy to analyse. In an unorientated sample, as most membrane preparations are, the deuterium quadrupole interactions give rise to a characteristic powder-pattern. The spectrum has two distinct peaks, the separation of which is the so-called deuterium quadrupole splitting $\Delta v_{\mathrm{Q}}$. The deuterium quadrupole splitting may be used to calculate the deuterium order parameter $S_{\mathrm{CD}}$ according to

$$
\Delta \nu_{Q}=\left(\frac{3}{4}\right)\left(e^{2} q Q / h\right) S_{\mathrm{CD}}
$$

The deuterium order parameter is a measure of the motional anisotropy of the particular $\mathrm{C}-\mathrm{D}$ bond investigated. If $\Theta$ denotes the instantaneous angle between the $\mathrm{C}-\mathrm{D}$ bond and the direction of the bilayer normal then $S_{\mathrm{CD}}$ is defined as

$$
S_{\mathrm{CD}}=\left(\frac{1}{2}\right)\left(3 \overline{\cos ^{2} \Theta}-\mathrm{I}\right),
$$

where the bar denotes the time average.

Only the absolute value of the deuterium order parameter can be determined from equation (I) since the sign of the quadrupole splitting is generally unknown. The static deuterium quadrupole coupling constant is $170 \mathrm{kHz}$ for aliphatic C-D bonds (Burnett \& Muller, 197 I) and about $175 \mathrm{kHz}$ for olefinic $\mathrm{C}-\mathrm{D}$ bonds (Kowalewski et al. 1976; Achlama \& Zur, 1979). It is not affected very much by the chemical nature of adjacent substituents.

The power of deuterium $\mathrm{nmr}$ is illustrated in Fig. I for bilayers of phosphatidylglycerol where the three methylene segments of the glycerol head group have been deuterated (Wohlgemuth, WaespeŠrčevic \& Seelig, I980). The ${ }^{2} \mathrm{H}-\mathrm{nmr}$ spectrum of the perdeuterated phosphatidylglycerol (uppermost spectrum) shows three quadrupole splittings which can be assigned to the individual headgroup segments 


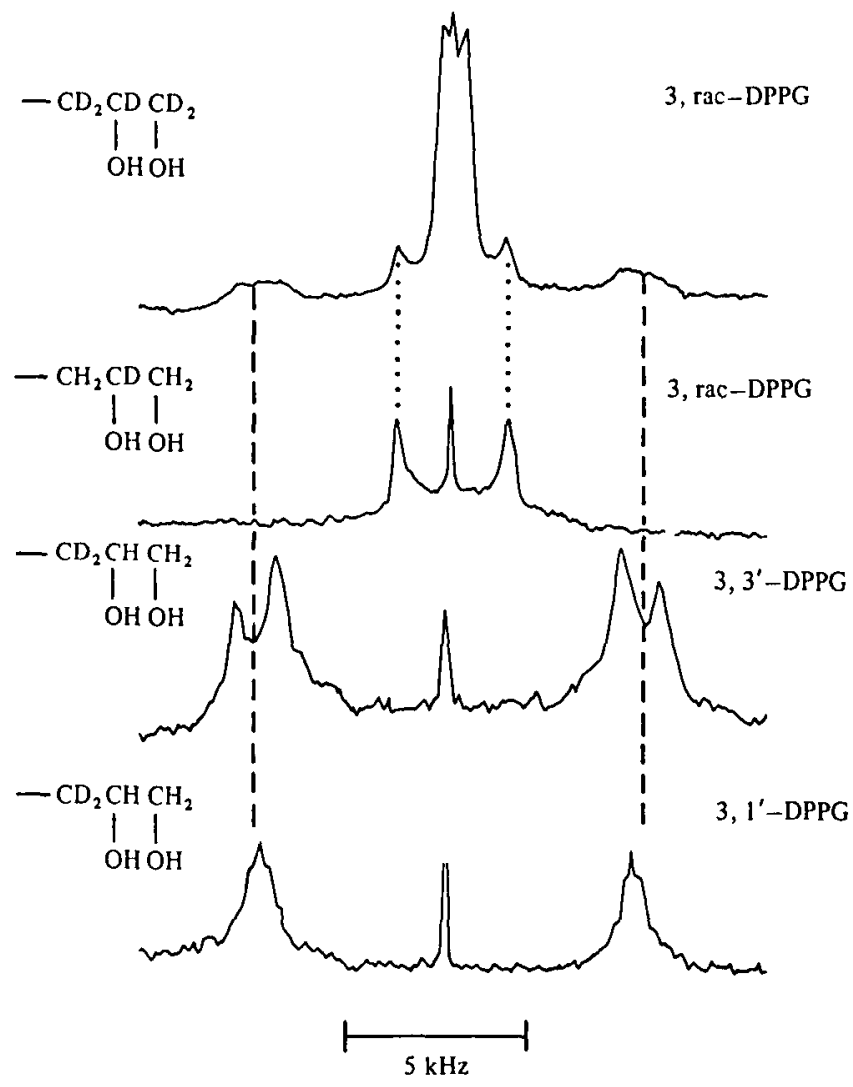

pH $7 \cdot 0 ; \quad 0.1 \mathrm{M} \cdot \mathrm{NaCl}$

$43^{\circ} \mathrm{C}$

Fig. I. Bilayers of phosphatidylglycerol deuterated at various headgroup segments. 3,I'-DPPG $\triangleq$ 1,2-dipalmitoyl-sn-glycero-3-phospho-I'-glycerol (naturally occurring $\mathrm{L}, \mathrm{D}$ conformation).

$3,3^{\prime}$-DPPG is the corresponding $\mathrm{L}, \mathrm{L}$ enantiomer, while 3 , rac-DPPG represents an equimolar mixture of the two diastereomers. The sodium salts of the corresponding lipids were dispersed in buffer to form coarse liposomes. ( $\sim 15$ wt $\%$ lipid, excess PIPES buffer pH $7 \cdot 0,0.1 \mathrm{M}-\mathrm{NaCl}$ ). The 'H-nmr measurements were made at $6 \mathrm{r} \cdot 4 \mathrm{MHz}$ at a temperature of $43{ }^{\circ} \mathrm{C}$ (gel-to-liquid crystal phase transition temperature $4 \mathrm{I}^{\circ} \mathrm{C}$ ). Reproduced with permission from Wohlgemuth et al. (1980).

by comparison with the selectively labelled compounds. Fig. I demonstrates that the three head-group segments, though chemically rather similar, are characterized by distinctly different residual quadrupole splitting constants $\Delta v_{Q}$ and, consequently, have different motional properties. The sensitivity of ${ }^{2} \mathrm{H}-\mathrm{nmr}$ is further exemplified by the 
observation that it is possible to differentiate clearly between the $\mathrm{L}$ and D configuration of the head group $\left(3,3^{\prime}-\right.$ DPPG and $3, \mathrm{r}^{\prime}-\mathrm{DPPG}$ in Fig. I). Under favourable circumstances one may even resolve the two deuterons of a $\mathrm{CD}_{2}$ group individually (cf. the spectrum of $\mathrm{CH}_{2}$ $\mathrm{CH}-\mathrm{CD}_{2}-3,3^{\prime}-\mathrm{DPPG}$ in Fig. I and Wohlgemuth et al. 1980).

The deuterium quadrupole couplings, $\Delta v_{Q}$, are mainly determined by the average conformation of the phospholipid molecules and the amplitudes of the oscillations of the individual segments and therefore provide structural information about the membrane system. Knowledge of the C-D bond order parameter, however, does not in general determine the complete order tensor of the rigid $\mathrm{CD}_{2}$ group. Additional measurements of, for example, $\mathrm{H}-\mathrm{D}$ or $\mathrm{D}-\mathrm{D}$ couplings are required or judicial assumptions must be made in order to complete the structural analysis.

Measurement of deuterium nmr relaxation times sheds light on the dynamics of the phospholipid molecules. Here the advantage is that the relaxation of the ${ }^{2} \mathrm{H}$ nucleus is dominated exclusively by quadrupole relaxation which considerably simplifies the interpretation of the deuterium relaxation times. A detailed description of the quantitative analysis of deuterium $\mathrm{nmr}$ spectra and relaxation times may be found in two review articles (Seelig, 1977; Mantsch, Saito \& Smith, 1977).

Due to instrumental limitations ${ }^{2} \mathrm{H}-\mathrm{nmr}$ spectroscopy was originally restricted to the fluid (liquid-crystalline) state of membranes. The introduction of the quadrupole-echo method has considerably widened the range of applications and has made it possible to observe also the very broad resonances of gel-state lipids (Davis et al. 1976). An additional complication occurs with gel-state spectra because they cannot be characterized by a single order parameter. Bloom and co-workers suggest the use of an order distribution function $p(S)$ such that, for a quasicontinuous distribution of $S, p(S) \mathrm{d} S$ is the probability of finding an orientational order parameter between $S$ and $S+\mathrm{d} S$. This distribution function can be related to the moments of the ${ }^{2} \mathrm{H}-\mathrm{nmr}$ spectrum in a rather straightforward manner (Davis et al. 1979). 


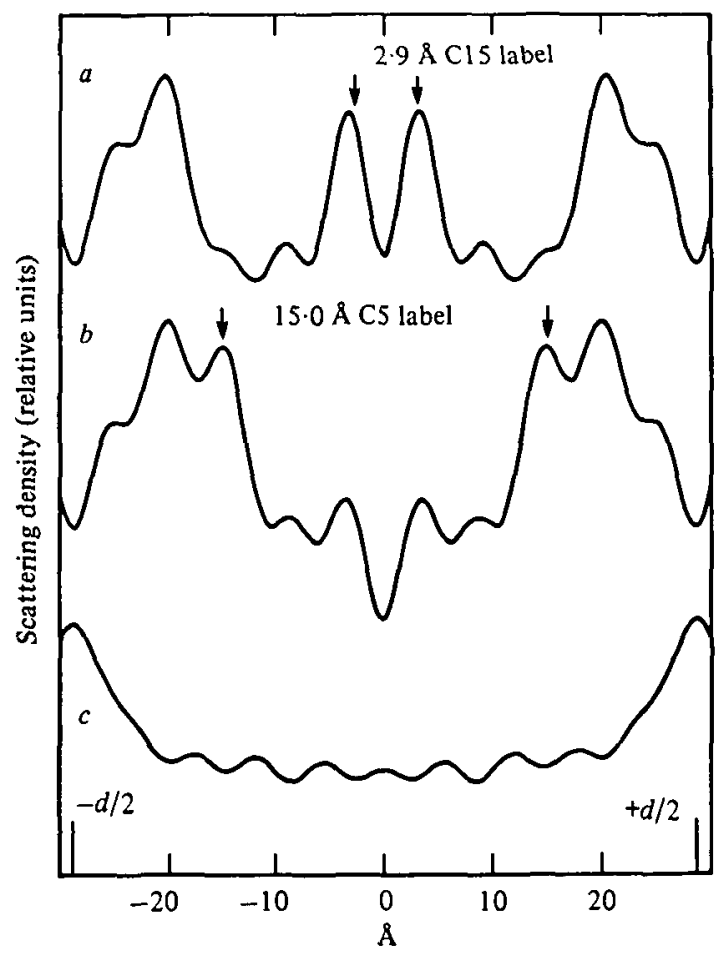

Fig. 2. Neutron diffraction profiles of I,2-dipalmitoyl-sn-glycero-3-phosphocholine at low water content $(5-6 \mathrm{wt} \%)$ and $20^{\circ} \mathrm{C}$. (a) Deuterated at the C-I 5 segment of both hydrocarbon chains. (b) At the C-5 position of both chains. (c) The water distribution as determined from the difference profile of $\mathrm{C}_{-5}$ deuterated lipid in $\mathrm{D}_{2} \mathrm{O}$ and $\mathrm{H}_{2} \mathrm{O}$. The lamellar spacing was $67.4 \mathrm{~A}$. Reproduced with permission from Büldt et al. (1978).

\section{NEUTRON DIFFRACTION}

The synthesis of selectively deuterated phospholipids is generally quite time-consuming and in view of the labour involved it is rather rewarding that the same compounds can also be employed with much success in neutron diffraction studies. In contrast to $\mathrm{X}$-rays which are scattered at the electrons, the scattering centres for neutrons are the atomic nuclei. In neutron diffraction the coherent scattering amplitudes of the two isotopes ${ }^{1} \mathrm{H}$ and ${ }^{2} \mathrm{H}$ are distinctly different, permitting an easy localization of the deuterated site in the scattering density profiles (for a review see Worcester, 1976). This is illustrated in more detail in Fig. 2 for bilayers of 1,2-dipalmitoyl-sn-glycero-3-phosphocholine 
(DPPC), which are deuterated at specific sites of the fatty acyl chains (Büldt et al. 1978). The measurements were made with homogeneously orientated bilayers of DPPC in the gel state and $6 \mathrm{wt} \%$ water content. Distances are measured from the centre of the bilayer, i.e. from the contact area of the two juxtaposed monolayers. In Fig. $2(a)$ the deuterons are attached at the C-r 5 carbon atom of both fatty acyl chains and one observes intense scattering density in the bilayer interior. The additional scattering intensity around $\pm 20 \AA$ results from the oxygens and the phosphorus contained in the polar groups. If the deuterons are moved further up to the polar group as in Fig. $2(b)$, the peaks at the C-I 5 position are lost and are replaced by a trough, characteristic of the low scattering intensity of non-deuterated terminal methyl groups. At the same time new intensity appears at $\pm{ }_{5} \AA$, indicating the position of the deuterated $\mathrm{C}-5$ carbon segments. Thus, neutron diffraction combined with the use of deuterated lipids allows an unambiguous determination of the average position of the ${ }^{2} \mathrm{H}$-labelled segment in the membrane. In addition, the width of the peaks in the scattering density profile is a measure of the amplitudes of the positional fluctuations around the segmental equilibrium position (Büldt et al. 1979). Fig. $2(c)$ is the difference Fourier profile of DPPC bilayers swollen in $\mathrm{H}_{2} \mathrm{O}$ and $\mathrm{D}_{2} \mathrm{O}$. The resulting scattering density curve describes the distribution of $\mathrm{D}_{2} \mathrm{O}$ molecules between the bilayers. From such $\mathrm{D}_{2} \mathrm{O} / \mathrm{H}_{2} \mathrm{O}$ exchange studies it can be concluded that water molecules penetrate into the lipid bilayer up to the level of the glycerol backbone (Worcester \& Franks, 1976).

\section{Phosphorus-3i NuClear magnetic Resonance}

No isotope-labelling is required for ${ }^{31} \mathrm{P}-\mathrm{nmr}$ spectroscopy since the natural abundance of this isotope is $100 \%$. ${ }^{31} \mathrm{P}-\mathrm{nmr}$ spectroscopy therefore offers an easy access to the headgroup region of phospholipids. Phosphorus $\mathrm{nmr}$ spectra of unsonicated lipid dispersions are characterized by a typical shape which is illustrated in Fig. 3 (uppermost spectrum). The spectral shape is determined by the chemical shift anisotropy of the phosphorus nucleus which is only partially averaged in phospholipid bilayers (for a review see Seelig, 1978). The residual chemical shift anisotropy, $\Delta \sigma=\sigma_{\|}-\sigma_{\perp}$, can easily be determined from the edges of the spectrum (cf. Fig. 3 ) and is a measure of the orientation and average fluctuation of the phosphate segment. Like the deuterium 

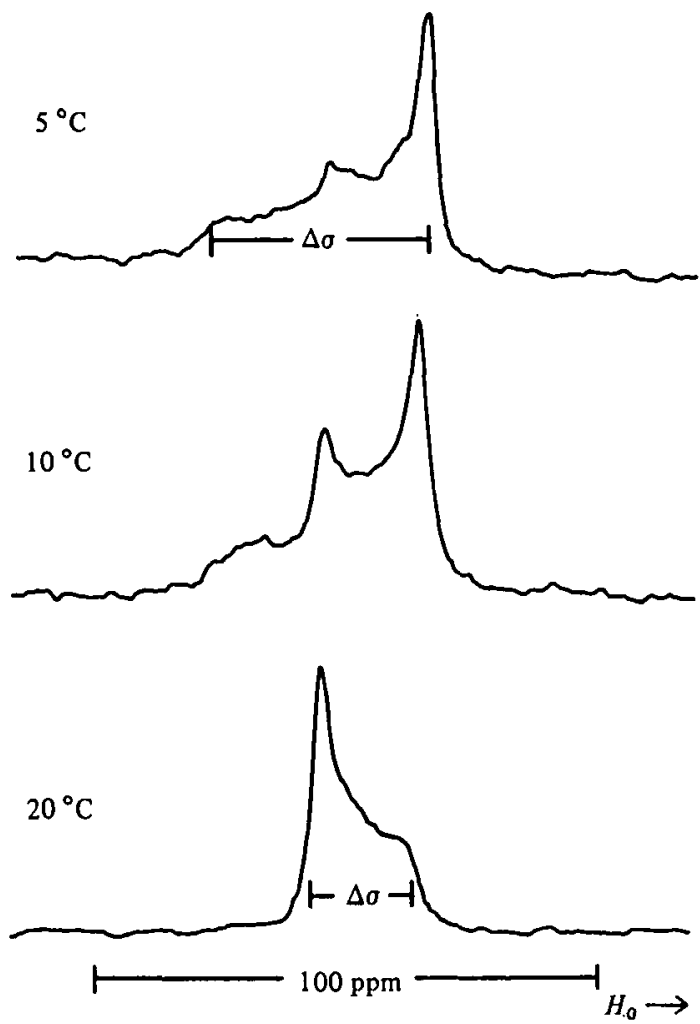

Fig. 3. Phosphorus-3 I nmr spectra obtained from aqueous dispersions of I,2-dioleoyl-sn-glycero-3-phosphoethanolamine demonstrating the change from a lamellar structure at $5{ }^{\circ} \mathrm{C}$ to a hexagonal structure at $20^{\circ} \mathrm{C}$. Reproduced with permission from Cullis \& de Kruijff (1976).

quadrupole coupling, $\Delta v_{Q}$, the phosphorus chemical shielding anisotropy, $\Delta \sigma$, results from the averaging of a tensorial property, this time the chemical shielding tensor. Since the molecularly fixed chemical shielding tensor is not axially symmetric (Griffin, 1976; Kohler \& Klein, 1976; Herzfeld, Griffin \& Haberkorn, 1978) the molecular interpretation of $\Delta \sigma$ is more complicated and requires two order parameters (Niederberger \& Seelig, 1976) instead of one for deuterium nmr. However, even without a detailed molecular interpretation, $\Delta \sigma$ may be used as a convenient measure for the comparison of headgroup motion in different lipid bilayers. An interesting property of phosphorus $\mathrm{nmr}$ is its sensitivity to lipid polymorphism (for a review see Cullis \& de Kruijff, 1979). If the geometry of the lipid phase changes from lamellar 
to hexagonal the phosphorus chemical shielding anisotropy, $\Delta \sigma$, changes its sign and is reduced by exactly a factor of two, assuming constant head group conformation. This transition is illustrated in Fig. 3. In the hexagonal phase the lipids are arranged in cylindrical rods with rapid diffusion of the lipid molecules around the cylinder axis (Seelig \& Limacher, I974; Mely, Charvolin \& Keller, 1975). The additional averaging motion of the phospholipids quite naturally leads to the above mentioned quantitative explanation of the observed spectral changes. A third type of spectrum can be observed if the phospholipid molecules move rapidly through all angles in space. Such an 'isotropic' tumbling may be encountered in a variety of experimental conditions, i.e. in solution, in micelles, in cubic or rhombic phases, or in highly curved lipid bilayers as, for example, single-walled vesicles of small diameter. Such isotropic motions, regardless of their molecular origin, will produce a complete averaging of the phosphorus chemical shift anisotropy and the spectrum then consists of a single sharp line. It is obvious that the observation of such a line in a system of unknown composition cannot be used for structural elucidation.

\section{STRUCTURE OF THE HYDROCARBON REGION}

\section{(1) Bent and straight hydrocarbon chains}

From a chemical point of view the two hydrocarbon chains of a synthetic lipid such as I,2-dipalmitoyl-sn-glycero-3-phosphocholine (DPPC) are completely equivalent and it is reasonable to assume a priori identical conformations for the two chains. This idea is however not borne out by the experimental results. Fig. $4 \mathrm{~A}$ shows ${ }^{2} \mathrm{H}-\mathrm{nmr}$ spectra of DPPC labelled in both fatty acyl chains at the $\mathrm{C}-2$ segment, i.e. the segment next to the ester carbonyls. A single quadrupole splitting is expected if the chain conformations are the same, but instead the spectrum is characterized by three doublets of quite different separation. By labelling the chains individually the largest signal can be assigned to the $s n$ - I chain while the two smaller signals arise from the $s n-2$ chain

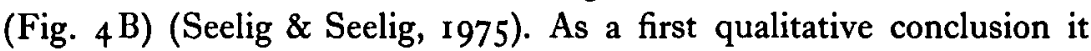
follows that the two chains of DPPC are physically inequivalent and adopt different average conformations in the liquid-crystalline bilayer. Subsequent studies on other lipid systems showed that this spectral pattern is indeed a very general property of all natural phospholipids 
28 J. SEELIG AND ANNA SERLIG

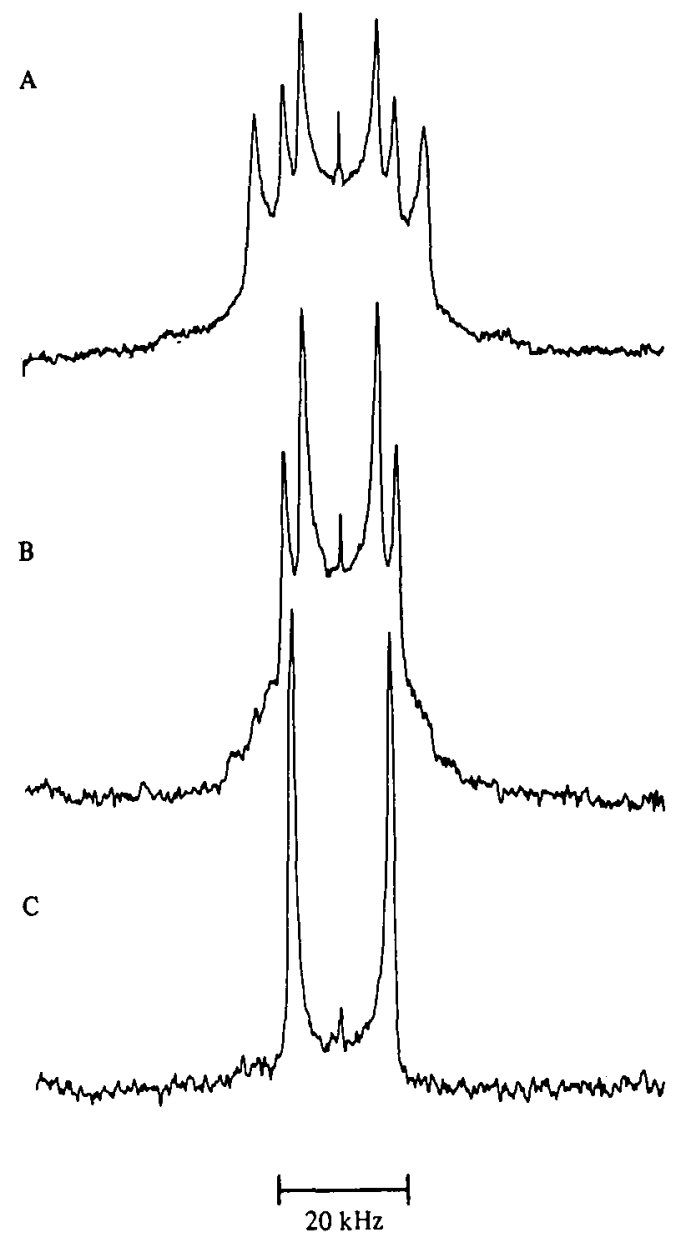

Fig. 4. ${ }^{2} \mathrm{H}$-nmr spectra of bilayers of 1,2 -dipalmitoyl-sn-glycero-3-phosphocholine (A, B) and 1,3-dipalmitoyl-sn-glycero-2-phosphocholine (C). The palmitic acyl chain is always deuterated at the C-2 position. (A) sn-3-DPPC, both chains labelled. (B) $s n-3-D P P C$, only $s n-2$ chain labelled. (C) $s n-2$ DPPC, both chains labelled. ${ }^{2} \mathrm{H}$-nmr measurements $(46.06 \mathrm{MHz})$ were made using the quadrupole echo technique. $\sim 50 \mathrm{wt} \% \mathrm{H}_{2} \mathrm{O}, 315{ }^{\circ} \mathrm{K}$. (Cf. Seeling et al. 1980.)

investigated so far, independent of the chemical nature of the polar group or the hydrocarbon chains. The qualitative and quantitative similarity of the different systems is summarized in Fig. 5. This plot shows the temperature dependence of the deuterium order parameters, $S_{\mathrm{CD}}$, of the C-2 segment for phospholipid bilayers composed of different

Downloaded from https://www.cambridge.org/core. WWZ Bibliothek, on 14 Nov 2017 at 10:32:42, subject to the Cambridge

Core terms of use, available at https://www.cambridge.org/core/terms. https://doi.org/10.1017/S0033583500000305 


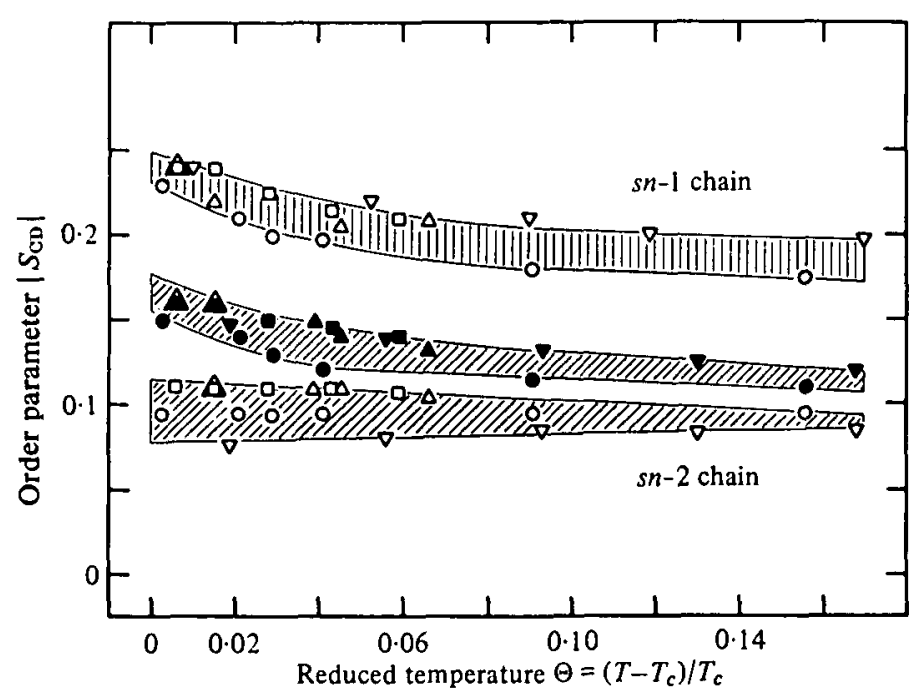

Fig. 5. Variation of the deuterium order parameter $\left|S_{\mathrm{CD}}\right|$ of the fatty acyl chain $\mathrm{C}-2$ segments with the reduced temperature. $\nabla, \mathrm{i}$-palmitoyl-2-oleoylsn-glycero-3-phosphocholine; $O$, 1,2-dipalmitoyl-sn-glycero-3-phosphocholine; $\square$, I,2-dipalmitoyl-sn-glycero-3-phosphoserine; $\Delta, 1,2$-dipalmitoyl$s n$-glycero-3-phosphoethanolamine. Reproduced with permission from Seelig \& Browning (1978).

head groups (choline, ethanolamine, serine) and fatty acyl chains (saturated and unsaturated) (Seelig \& Browning, 1978). The deuterium order parameters have been normalized by referring them to a reduced temperature $\Theta=\left(T-T_{c}\right) / T_{c}\left(T \hat{=}\right.$ measuring temperature, $T_{c} \hat{=}$ gelto-liquid crystal transition temperature; $T, T_{C} \hat{=}{ }^{\circ} \mathrm{K}$ ). The rationale is to eliminate all effects caused by differences in the gel-to-liquid crystal transition temperatures, which range from $-5{ }^{\circ} \mathrm{C}$ for POPC to $63{ }^{\circ} \mathrm{C}$ for DPPE (DPPC $4 \mathrm{I}{ }^{\circ} \mathrm{C}$; DPPS $5^{\mathrm{I}}{ }^{\circ} \mathrm{C}$ ). At $\Theta=0$ each bilayer is at its respective phase transition temperature. The actual temperature range in Fig. 5 extends from -5 to $90^{\circ} \mathrm{C}$. Nevertheless, all the data are collected in rather narrow bands supporting the hypothesis of a similar physical state at a given $\Theta$ temperature. A ${ }^{2} \mathrm{H}-\mathrm{nmr}$ study of a glycolipid, $N$-palmitoylgalactosylceramide, has yielded a similar result. Immediately above the gel-to-liquid crystal phase transition $\left(90^{\circ} \mathrm{C}\right)$ two sets of quadrupole splittings with 18 and $25 \mathrm{kHz}$ separation are observed for the $\mathrm{C}-2$ segment of the palmitic acyl chain, corresponding in size and shape to the $s n-2$ chain of natural phospholipids (Skarjune \& Oldfield, I979a). 
$\left[2,2-d_{2}\right]$ elaidic acid

A

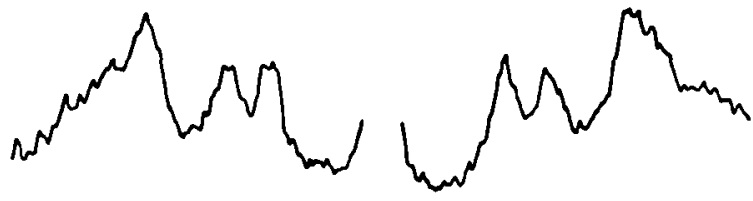

B

Liposomes

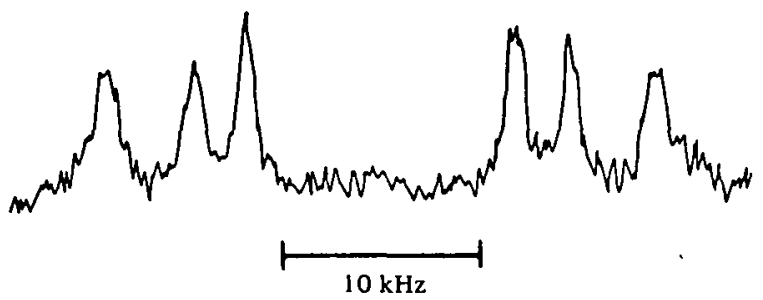

Fig. 6. ${ }^{2} \mathrm{H}-\mathrm{nmr}$ spectra $(6 \mathrm{r} \cdot 4 \mathrm{MHz})$ of $\left[2,2^{2} \mathrm{H}_{2}\right]$ elaidate enriched strain $E$. coli cells (strain T2 GP). (A) intact cells, $36^{\circ} \mathrm{C}$. (B) Liposomes derived from elaidate enriched cells, $4 \mathrm{I}^{\circ} \mathrm{C}$. Reproduced with permission from Gally et al. (1979).

The discussion has been limited so far to pure lipid-water systems and it could be argued that the situation is different in biological membranes where the phospholipid conformation is modulated by the presence of membrane proteins. However, if $\mathrm{C}-2$ deuterated fatty acids are added to the growth medium of Escherichia coli bacteria it is possible to obtain in vivo incorporation of the fatty acids into $E$. coli phospholipids. The spectrum of intact cells (Fig. 6A) shows again the characteristic spectral 'fingerprint' of the C-2 position (i.e. three quadrupole splittings) which is furthermore virtually identical to the spectrum of liposomes formed from the extracted $E$. coli phospholipids (Fig. 6B) (Gally et al. 1979). This is a remarkable result since it demonstrates that the conformation of the phospholipid molecule at the C-2 segments is not altered to any appreciable extent by the presence of $60-70 \mathrm{wt} \%$ protein. A second in vivo system which has been studied by ${ }^{2} \mathrm{H}-\mathrm{nmr}$ is Acholeplasma laidlawii (Stockton et al. 1977; Rance et al. 1980). Again the results obtained for the $\mathrm{C}-2$ position are completely consistent with the spectral pattern discussed above.

Having established the rather general and unique character of the ${ }^{2} \mathrm{H}$-nmr spectrum of the $\mathrm{C}-2$ position the next step is to derive the underlying molecular picture. This is possible by a quantitative analysis of the size of the quadrupole splittings. The difference in the quadrupole 
splittings can be explained by a conformational model in which the beginnings of the two fatty acyl chains have different average orientations with respect to the bilayer surface (Seelig \& Seelig, 1975; Schindler \& Seelig, I975). In particular, the $s n$-I chain is extended perpendicular to the bilayer surface at all segments while the first $\mathrm{CH}_{2}$ segment of the $s n-2$ chain is orientated parallel to the surface of the membrane and the chain is bent sharply beyond this segment to also assume an orientation perpendicular to the bilayer surface. As a consequence of this bend of the $s n-2$ chain the two chains remain out-of-step throughout the bilayer and the $s n$-I chain penetrates more deeply into the bilayer than the $s n-2$ chain. In naturally occurring lipids the $s n-2$ chain is often found to be longer than the adjacent $s n$-I chain (cf. van Deenan, 1965). The bend in the $\boldsymbol{s n - 2}$ chain would partially compensate this difference and would minimize packing problems. The axial displacement of the two chains is also sensed, though less dramatically at other positions and the corresponding ${ }^{2} \mathrm{H}-\mathrm{nmr}$ results have been discussed in an earlier review (Seelig, 1977).

Neutron diffraction studies of deuterated I,2-dipalmitoyl-sn-glycero3-phosphocholine (DPPC) and I,2-dipalmitoyl-sn-glycero-3-phosphoethanolamine (DPPE) in the gel-state allow a determination of the mean label position to an accuracy of \pm I $\AA$. For DPPC at $6 \%(w / w)$ water and $20{ }^{\circ} \mathrm{C}$ the $\mathrm{C}-2$ seg ment of the $s n-2$ chain is about $2 \AA$ closer to the surface of the bilayer then the $\mathrm{C}-2$ segment of the $s n-\mathrm{I}$ chain (Zaccai et al. 1979). For DPPE in the gel-state the axial displacement of the two chains is slightly larger and amounts to $3-4 \AA$ (Büldt \& Seelig, 1980).

X-ray structural analysis of phospholipids has been hampered by the difficulty of growing single crystals of appropriate size and quality. However, during the last five years the first two structures have been solved. Single crystals have been obtained for I,2-dilauroyl-racglycero-phosphoethanolamine (Hitchcock et al. 1974) crystallized from acetic acid and for hydrated 1,2-dimyristoyl-sn-glycero-3-phosphocholine (Pearson \& Pascher, 1979) and a very similar conformation is assumed by the two molecules (cf. Fig. 7). In both crystals the $s n$-I chain takes up the extended all-trans conformation while the initial part of the $s n-2$ chain extends parallel to the bilayer surface and bends off at the second chain segment to become parallel to the $s n$-I chain. The axial displacement between the two fatty acyl chains in both crystals corresponds to about 3 methylene groups. 


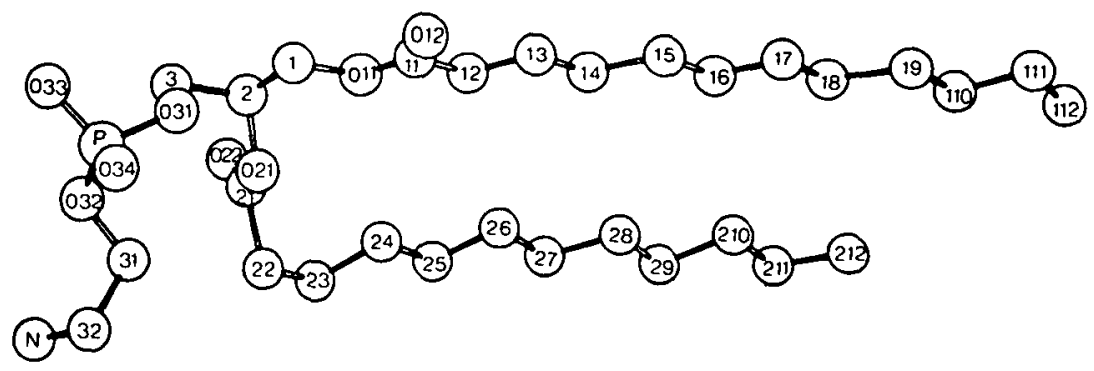

Fig. 7. The molecular conformation of rac-1,2-dilauroyl-glycero-3-phosphoethanolamine crystallized in bilayer form from acetic acid. Reproduced with permission from Hitchcock et al. (1974).

Taken together these studies demonstrate quite convincingly that the rather unexpected orientation of the beginnings of the two fatty acyl chains is a ubiquitous phenomenon, typical of model membranes as well as intact biological membranes, and independent of the physical state (crystal, gel or liquid-crystal). Some quantitative differences do exist, however, with respect to the dynamics of the system and the extent of axial displacement of the two chains. In the crystal the individual atoms are fixed to their lattice sites and the axial displacement is exactly $3 \cdot 7 \AA$, corresponding to three carbon-carbon bonds (effective length $\mathrm{I} \cdot 25 \AA$ per bond). The physical state of the gel-phase is less well characterized, but ${ }^{2} \mathrm{H}-\mathrm{nmr}$ and Raman studies on simple model membranes such as DPPC suggest that the lipid molecules are undergoing a rapid reorientation about their long axes combined with a small number of trans-gauche isomerizations around $\mathrm{C}-\mathrm{C}$ bonds (Davis, 1979; Gaber \& Peticolas, 1977). These limited motions reduce the axial displacement of the two chains to about $2 \AA$ (or 15 carbon-carbon bonds) as evidenced by neutron diffraction (Zaccai et al. 1979). Finally, above the phase transition temperature the membrane becomes highly fluid, endowing the individual phospholipid molecules with a much larger flexibility than found in the gel phase. The observed quadrupole splittings are the result of a dynamic equilibrium between various conformational states. For the $\mathrm{C}-2$ segment of the $s n-2$ chain the parallel segment orientation has by far the largest statistical weight. Nevertheless, there is still a small but finite probability that for a brief period of time the first part of the $s n-2$ chain is orientated perpendicular to the bilayer surface (for details cf. Schindler \& Seelig, I975). 
The C-2 segment of the $s n-2$ chain gives rise to two quadrupole splittings. The occurrence of two splittings for the same methylene segments can be accounted for by two different models. One possibility would be the assumption of two long-lived conformations of the lipid molecule with two different orientations for chain 2. This model was originally suggested because of the different temperature dependence of the two signals (Seelig \& Seelig, 1975) and was again proposed recently by Rance $e t$ al. (1980) on the basis of an intensity comparison of the two ${ }^{2} \mathrm{H}-\mathrm{nmr}$ signals. An alternative possibility would be that the two deuterium atoms of the $\mathrm{CD}_{2}$ group are motionally inequivalent and thus produce two different signals. A decision between the two models could be made by stereospecific incorporation of just one deuteron into the C-2 segment. In two analogous situations, i.e. the phosphoglycerol head group of 1,2-dipalmitoyl-sn-glycero-3-phospho-3'-glycerol (Wohlgemuth et al. 1980) and the glycerol backbone of DPPC (N. Waespe-Sarčevic \& J. Seelig, unpublished) the stereoselective mono-deuteration has indeed simplified the spectra and eliminated one set of quadrupole splittings.

An unusual result has been obtained for bilayers composed of $s n-2$ phosphocholines. In these molecules the fatty acyl chains are attached to carbon atoms $I$ and 3 of the glycerol backbone while the phosphocholine moiety is linked to the $s n-2$ segment. A much simpler spectral pattern is observed for $1,3-\mathrm{di}\left[2,2-{ }^{2} \mathrm{H}_{2}\right]$ palmitoyl-sn-glycero-2-phosphocholine than for the $\mathrm{I}, 2$-analogue. Fig. ${ }_{4} \mathrm{C}$ demonstrates that both chains and all four deuterons are characterized by the same quadrupole splitting. The size of the quadrupole splitting of the I,2-DPPC is identical to the average of the two smaller splittings ( $s n-2$ chain) of I,2-DPPC (Seelig, Dijkman \& de Haas, I980). This then suggests that in $1,3-D P P C$ both fatty acyl chains adopt a bent conformation which is also supported by the expanded surface area of this molecule in monolayer experiments. This result may be of relevance in connexion with the action of phospholipase $A_{2}$ on phospholipid molecules. The enzyme stereospecifically cleaves natural phospholipids at the $s n-2$ position, i.e. at the bent chain. If $s n-2$ phosphatidlylcholines are offered as a substrate, both the $s n-\mathrm{I}$ or the $s n-3$ chain can potentially be split off. Which chain is attacked is determined solely by the configuration at the optical centre of the glycerol backbone.

\section{(2) Order profiles of model membranes and biological membranes}

While a rather detailed molecular picture has emerged for the beginnings of the two fatty acyl chains of a phospholipid molecule, no specific conformation can be singled out to describe the rest of the hydrocarbon 
region. Owing to rapid trans-gauche isomerizations around carboncarbon bonds (jump rate $\sim 10^{10} \mathrm{~Hz}$, Flory (1969)) the chains are highly flexible, assuming many different conformations within a very short period of time. The liquid-like character of the bilayer interior is however different from that of a simple paraffinic melt. The $\Delta H$ values associated with the gel-to-liquid crystal transition are lower than the $\Delta H$ values for the melting of pure hydrocarbons. The same holds true for the entropy change in the process. The incremental $\Delta S$ per $\mathrm{CH}_{2}$ group is only about $\mathrm{I}$ e.u. for the gel-to-liquid crystal transition of bilayers but is almost twice as large for the melting of simple paraffins (Phillips, Williams \& Chapman, I969). These thermodynamic results already suggest that the hydrocarbon chains in the bilayer core are not as disordered as they are in a pure liquid hydrocarbon.

A quantitative characterization of the local orientational order of the fatty acyl chains is possible with deuterium nmr. By selectively labelling each segment of the hydrocarbon chain one can measure the order parameter, $S_{\mathrm{Cu}}$, of the individual segments. Assuming axial symmetry of the segment motion $S_{\mathrm{CD}}$ can further be related to the molecular order parameter $S_{\mathrm{mol}}$ according to (Seelig \& Niederberger, 1974)

$$
S_{\mathrm{mol}}=-2 S_{\mathrm{CD}}
$$

If the chains are fixed in the all-trans conformation and are just rotating around the long molecular axis, the molecular order parameter $S_{\text {mol }}$ would be unity. The other extreme is that of a completely statistical movement through all angles of space, leading to $S_{\mathrm{mol}}=0$. This simple statistical interpretation of $S_{\mathrm{CD}}$ is not possible if specific geometric effects come into play as, for example, in the case of the cis-double bond (cf. below). The order profile of a lipid bilayer shows the variation of the order parameter, $S_{\mathrm{mol}}$ or $S_{\mathrm{CD}}$, with the position of the segment in the chain and is an expression of the average angular fluctuations around the bilayer normal. The order profile is amenable to statistical-mechanical interpretations and is also related to the positional fluctuations as determined by neutron diffraction (Zaccai et al., 1979). An extensive discussion of some physical aspects of order profiles has been given elsewhere (Seelig, 1977) and only a few pertinent features will be reiterated here.

In view of the considerable effort required for the synthesis of selectively deuterated phospholipids it is not surprising that the number 


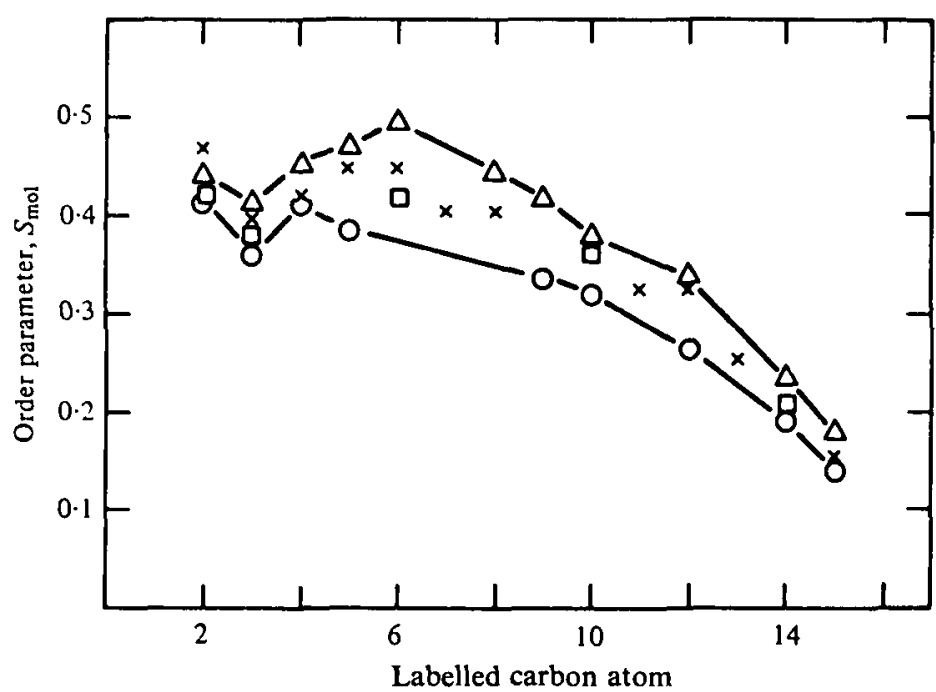

Fig. 8. Normalized order profiles of different bilayers. Variation of the molecular order parameter, $S_{\mathrm{mol}}$, with the segment position. $O$, I, 2-dipalmitoylsn-glycero-3-phosphocholine. $\Delta, 1$-palmitoyl-2-oleoyl-sn-glycero-3-phosphocholine. $\square$, I,2-dipalmitoyl-sn-glycero-3-phosphoserine. $\times$, Acholeplasma laidlawii (Stockton et al 1977). Reproduced with permission from Seelig \& Browning ( 1978 ).

of order profiles reported in the literature is still small. ${ }^{2} \mathrm{H}-\mathrm{nmr}$ order profiles using selectively deuterated phospholipids have been established now for 1,2-dipalmitoyl-sn-glycero-3-phosphocholine (DPPC) (Seelig \& Seelig, 1974, 1975), 1,3-dipalmitoyl-sn-glycero-3-phosphocholine (Seelig et al. 1980), 1,2-dimyristoyl-sn-glycero-3-phosphocholine (Oldfield et al. 1978a, $b$ ) I-palmitoyl-2-oleoyl-sn-glycero-3-phosphocholine (POPC) (Seelig \& Seelig, I977; Seelig \& Waespe-Sarčevic, 1978) and 1,2-dipalmitoyl-sn-glycero-3-phosphoserine (DPPS) (Seelig \& Browning, 1978; Browning \& Seelig, 1980). In addition, egg-yolk lecithin with perdeuterated palmitic acyl chains intercalated physically (Stockton et al., 1976), perdeuterated 1,2-dipalmitoyl-sn-glycero-3phosphocholine (Davis, 1979) and a glycolipid (Skarjune \& Oldfield, 1979) have been studied. Though limited in number these order profiles comprise a fairly representative collection of different lipid classes, including saturated and unsaturated fatty acyl chains as well as different polar groups. In Fig. 8 the order profile of three synthetic phospholipids (POPC, DPPC, DPPS) are compared at a common reduced temperature, $\Theta=0.06 \mathrm{I}$, corresponding to actual measuring temperatures of 11,60 and $71{ }^{\circ} \mathrm{C}$ (Seelig \& Browning, 1978). All order 
profiles are remarkably similar. This similarity is reflected not only in the plateau region with relatively constant order parameters (carbon atoms 2-9) and the subsequent decrease of $S_{\text {mol }}$ towards the methyl terminal, but also in such details as the zig-zag in all order profiles at carbon atoms 2-4.

This characteristic signature of model membranes is carried over into biological membranes. Three order profiles of biomembranes are known in some detail to date. As a first example we have included in Fig. 8 the order profile of Acholeplasma laidlawii grown on perdeuterated palmitic acid (Stockton et al. 1977). This natural membrane has no well-defined transition temperature, instead it shows a rather broad transition around $25^{\circ} \mathrm{C}$. Referred to this approximate phase transition temperature $\left(T_{c}=298^{\circ} \mathrm{K}\right)$ the measuring temperature of $42^{\circ} \mathrm{C}$ corresponds to $\Theta=0.057$ which is tolerable for a comparison with the synthetic lipids at $\Theta=0.06 \mathrm{r}$. The agreement between the order profile of Acholeplasma laidlawii and those of the pure phospholipid membranes is striking. It is interesting to note that the extremes in Fig. 8 are defined by DPPC and DOPC while DPPS and the Acholeplasma laidlawii membrane fall in between these boundaries. Thus the incorporation of a cis-double bond is seen to promote larger changes in the order profile than, for example, the introduction of a net negative charge in the polar head group (DPPS) or the incorporation of proteins into the membrane. The divergence of the POPC order profile between carbon atoms $5^{-9}$ can be explained by a specific stiffening effect of the cis-double bond (Seelig \& Seelig, 1977).

As a second example we discuss ${ }^{2} \mathrm{H}-\mathrm{nmr}$ measurements of membranes of Escherichia coli grown on selectively deuterated palmitic as well as oleic acid (Gally et al. 1979). In Fig. 9 the order profile of intact $E$. coli cells is compared with that of a synthetic lipid, i.e. POPC. For palmitateenriched $E$. coli cells the order profile resembles that of the $s n$-I palmiticacyl chain of POPC; for the oleate-enriched cells, it agrees with that of the $s n-2$ oleic acyl chain. The order profile of the oleic acyl chain is unusual at first sight since the double bond appears as a pronounced discontinuity in the curve drawn through the order parameters. A quantitative analysis shows that the dip in the $S_{\mathrm{CD}}$ order profile of the oleic acyl chain is due to the geometry and the alignment of the cisdouble bond in the membrane. The most probable orientation of the cis-double bond is not exactly parallel to the bilayer normal but the $\mathrm{C}=\mathrm{C}$ vector is tilted by about $7-8^{\circ}$ with respect to this direction. After 


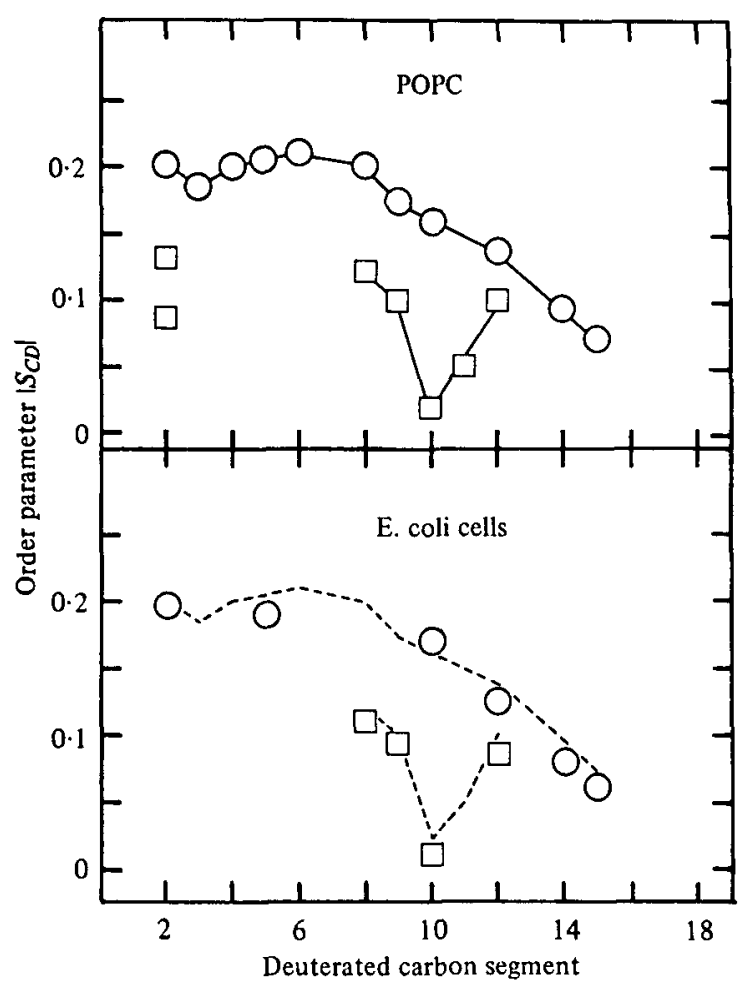

Fig. 9. Comparison between a biological membrane and a synthetic unsaturated lipid. Variation of the deuterium order parameter $\left|S_{\mathrm{CD}}\right|$ with segment position. POPC : I-palmitoyl-2-oleoyl-sn-glycero-3-phosphocholine; $50 \mathrm{wt} \%$ lipid; $27^{\circ} \mathrm{C} E$. coli cells: strains $\mathrm{T} 106 \mathrm{GP}$ and $\mathrm{T} 2 \mathrm{GP}$ grown on media supplemented with selectively deuterated palmitic or oleic acid, respectively. Temperature $40^{\circ} \mathrm{C}$. $O$, Deuterium label attached at palmitic acyl chain; $\square$, deuterium label attached at oleic acyl chain. Reproduced with permission from Gally et al. (1979).

correcting for this geometric factor, the molecular order parameters, $S_{\text {mol }}$, are identical within error limits in both chains (Seelig \& WaespeSarčevic̀, 1978). The main conclusion of this study is again the striking similarity between the shapes of the order profiles of $E$. coli cells and pure POPC, despite the fact that these cells are surrounded by two different membranes, have a heterogeneous fatty-acid composition, contain more than $50 \mathrm{wt} . \%$ protein in the membranes and have phosphoethanolamine and phosphoglycerol instead of phosphocholine as polar groups. Even minor details in the dynamic chain structure such as the average orientation of the cis-double bond are not distinctly modified by the presence of membrane-bound proteins. 
In a third in vivo study Acholeplasma laidlawii has been grown on oleic acid selectively deuterated at 15 different chain positions, leading to the most complete order profile of a biological membrane known to date (Rance et al. I980). Again, this order profile is characterized by a conspicuous dip at the position of the cis-double bond and is virtually superimposable on the order profile of synthetic POPC, lending further support to the conclusion that the orientational chain order of the phospholipids is not extensively perturbed by the membrane proteins.

Having established the close similarity of order profiles of model membranes and biological membranes at the same $\Theta$ temperature one can briefly discuss the molecular interpretation of this 'fluid bilayer signature' (Bloom, I979). Compared to neutron diffraction, which yields direct information on the segment positions, ${ }^{2} \mathrm{H}-\mathrm{nmr}$ provides less direct information and appropriate models for the chain flexing movements must be conceived.

Let us first consider the thickness of the phospholipid bilayer. It is intuitively reasonable that the segmental angular fluctuations (as measured by ${ }^{2} \mathrm{H}-\mathrm{nmr}$ ) and the average segment positions (as obtained by neutron diffraction) are linked together through the spectrum of conformations available to the fatty acyl chains. Based on trans-gauche isomerizations a simple model has been proposed to calculate distances between deuterated segments from the deuterium order parameters, $S_{\text {mol }}^{(i)}$, of the individual segments (Seelig \& Seelig, 1974; Schindler \& Seelig, 1975). The average chain length $\langle L\rangle$ of a fatty acyl chain with $n$ carbon-carbon bonds is found to be

$$
\langle L\rangle=\left(\frac{\mathrm{I}}{2 \cdot 25}\right)\left(\mathrm{r} \cdot 25 n+\sum_{i=1}^{n} S_{\mathrm{mol}}^{(i)}\right)
$$

Comparison with neutron diffraction data (Zaccai et al. I979; Oldfield et al. $1978 a, b$ ) shows that this calculation, while exceptionally simple, is nevertheless in excellent agreement with the scattering data. Using this procedure, bilayer thicknesses of the hydrocarbon region between 33 and $35 \AA$ have been calculated for DPPC and DPPS above the transition temperature (Seelig \& Seelig, r974; Browning \& Seelig, 1980). The all-trans state has a thickness of $45^{\circ} 9 \AA$ (measured from the ester bonds), thus the difference of 10-12 $\AA$ between these two values is the transbilayer contraction at the gel-to-liquid crystal transition (cf. Fig. 12 B).

An in-depth analysis of ${ }^{2} \mathrm{H}$-nmr profiles requires also more complicated statistical-mechanical theories. Most of the statistical theories suggested 
for lipid bilayers are primarily interested in the thermodynamic properties of bilayers, in particular in the change of the thermodynamic functions at the phase transition, and are not capable of explaining structural features such as the ${ }^{2} \mathrm{H}-\mathrm{nmr}$ order profile. Only one theory is available at present which also provides detailed insight into the microscopic structure of lipid bilayers (Marčelja, 1974) and this has been applied successfully to the ${ }^{2} \mathrm{H}-\mathrm{nm}$ r order profile of DPPC (Schindler \& Seelig, 1975). The basic features and results of this theory have been discussed earlier (Seelig, r977). A modification of the Marčeljamodel has been proposed by Gruen (1980). In contrast to Marčelja's original approach, the latter theory is limited to the liquid-crystalline state and does not permit any conclusions about the thermodynamic changes occurring at the phase transition. Another approach has been chosen by Meraldi and Schlitter (unpublished work), who have extended a generalized van-der-Waals theory of nematic liquid crystals to flexible molecules. In this model the chain-chain interaction is treated for the attractive forces in a molecular field approximation and for the repulsive forces by a hard core potential. The Meraldi-Schlitter model gives a precise account of the thermodynamic properties at the phase transition, allows an excellent simulation of the ${ }^{2} \mathrm{H}-\mathrm{nmr}$ order profile and its temperature dependence, predicts the average segment positions in agreement with the neutron diffraction data, and also calculates the packing density of the chains as reflected in the electron density profile of such systems (e.g. Cain, Santillan, \& Blasie, I 972). This complete and consistent picture of the available structural and thermodynamic data is provided within the frame of the rotational isomeric model; no chaintilting or rigid-body motion of the fatty acyl chains needs to be invoked.

Statistical-mechanical theories allow the calculation of conformational probabilities which are not accessible otherwise. From the simulations of the ${ }^{2} \mathrm{H}$-nmr order profile it can be concluded that each fatty acyl chain in DPPC above $T_{c}$ contains between 4 and 5 gauche rotamers, a value which is also supported by Raman spectroscopy (Gaber \& Peticolas, 1977), and other theoretical models. The calculation further shows that 'kink'-like structures, i.e. conformational sequences such as $\mathrm{g}^{+} \mathrm{tg}^{-}$, have a probability of less than 0.5 kinks per fatty acyl chain (cf. Seelig, I977). Thus the very appealing pure 'kink' model of lipid bilayers (Träuble, 197I) is not in accordance with the physical reality of a fluid lipid bilayer. 
Structural data at a microscopic level of phospholipid mesophases other than lamellar are still scarce. The interchain separation of hexagonal or inverted hexagonal mesophases gives rise to the same diffuse wide-angle $\mathrm{X}$-ray reflex at $\left(4^{6} 6 \AA\right)^{-1}$ as observed for lamellar bilayers (Luzzati, 1968). On the other hand, it is obvious that the different mesophase geometries must impose different packing constraints on the fatty acyl chains. This is indeed borne out by ${ }^{2} \mathrm{H}$-nmr experiments on 1,2-dielaidoyl-sn-glycero-3-phosphoethanolamine (DEPE). X-ray investigations suggest that unsaturated phosphatidylethanolamines have a strong tendency to form inverted hexagonal phases (Rand, Tinker \& Fast, 1971). In this structure a cylindrical core is made up from water molecules and this inner aqueous cylinder is surrounded by the lipid polar groups with the fatty acyl chains facing outward, forming a semiliquid hydrocarbon environment between the aqueous rods. Aqueous dispersions of DEPE show a transition from a lamellar phase at $4 \mathrm{I}^{\circ} \mathrm{C}$ to an inverted hexagonal phase at $6{ }_{1}^{\circ} \mathrm{C}$. (Cullis \& de Kruijff, 1978). The anchoring and structure of the polar head group at the lipid water interface is exactly the same in both phases as judged from the phosphorus chemical shielding anisotropy of the phosphate group and the deuterium quadrupole splitting of the $\mathrm{C}-2$ segment. By contrast, the quadrupole splittings of segments located further down the chain clearly show a considerable gain in configuration freedom in the hexagonal phase. The fatty acyl chains of the hexagonal phase must be packed less regularly than those of the bilayer phase (Gally et al. 1980).

\section{Phospholipid dynamics and membrane fuidity}

As has been emphasized before, the information obtainable from ${ }^{2} \mathrm{H}$ $\mathrm{nmr}$ is of two kinds. Measurement of the quadrupole splittings, $\Delta v_{Q}$, furnishes information about the time-averaged orientation of the segments involved. In contrast, measurement of the deuterium nmr relaxation times gives information on the rate of segmental motion. The correlation between chain order and chain mobility is not well understood as yet, and it is thus important to keep the two concepts apart. ${ }^{2} \mathrm{H}-\mathrm{nmr}$ is especially suited to yield experimental data on both aspects of membrane behaviour, but it should also be obvious that the distinction between time-averaged structural parameters (such as order pararneters) and dynamic parameters (such as relaxation times, correlation times and

† Data refer to both chains.

$\ddagger$ Unresolved resonances of carbon atoms $\mathrm{C}_{4}-\mathrm{C}_{13}$.

* Perdeuterated DPPC at $47^{\circ} \mathrm{C}$.

a Lee et al. (1976).

b Gally et al. (1975).

c Brown, Seelig \& Häberlen (1979).

d Davis (1979).

e Akutsu, J. Browning and J. Seelig (unpublished results). 
TABLE I. Spin-lattice relaxation times of DPPC

\begin{tabular}{|c|c|c|c|c|}
\hline $\begin{array}{l}\text { Segment } \\
\text { position }\end{array}$ & $\begin{array}{l}\text { Nomen- } \\
\text { clature }\end{array}$ & $\begin{array}{c}{ }^{18} \mathrm{C}-\mathrm{nmr} r^{8} \\
\text { sonicated ve- } \\
\text { sicles at } 5 \mathrm{I}^{\circ} \mathrm{C} \\
T_{1}(\mathrm{msec})\end{array}$ & $\begin{array}{c}{ }^{2} \mathrm{H}-\mathrm{nmr} \\
\text { coarse lipo- } \\
\text { somes at } 5 \mathrm{I}{ }^{\circ} \mathrm{C} \\
T_{1} \text { (msec) }\end{array}$ & $\begin{array}{c}{ }^{2} \mathrm{H}-\mathrm{nmr} \\
9: 1 \mathrm{CHCl}_{3} / \mathrm{Me}- \\
\mathrm{OH} \text { at } 5 \mathrm{I}{ }^{\circ} \mathrm{C} \\
T_{1} \text { (msec) }\end{array}$ \\
\hline$+\mathrm{N}\left(\mathrm{CH}_{3}\right)_{3}$ & $\mathrm{C} \gamma$ & $700 \pm 30$ & $80^{b}$ & - \\
\hline $\mathrm{CH}_{2}$ & $\mathrm{C} \beta$ & $320 \pm 80$ & $3^{8} \pm \mathrm{I}^{\mathrm{e}}$ & - \\
\hline $\mathrm{CH}_{2}$ & $\mathrm{C} \alpha$ & $270 \pm 60$ & $30 \pm I^{b, e}$ & - \\
\hline O & - & - & - & - \\
\hline $\mathrm{P}$ & - & - & - & - \\
\hline O & - & - & - & - \\
\hline $\mathrm{CH}_{2}$ & $\mathrm{G}_{3}$ & $110 \pm 20$ & $13 \cdot 3 \pm 1 \cdot 4^{c}$ & - \\
\hline $\mathrm{CH}$ & $\mathrm{G}_{2}$ & $100 \pm 30$ & - & - \\
\hline $\mathrm{CH}_{2}$ & $\mathbf{G}_{\mathrm{I}}$ & $100 \pm 30$ & - & - \\
\hline 0 & - & - & - & 一 \\
\hline $\mathrm{C}=\mathrm{O}$ & - & 一 & - & - \\
\hline $\mathrm{CH}_{2}$ & $\mathrm{C}_{2} \dagger$ & $100 \pm 20$ & $23 \cdot 4 \pm 3 \cdot 3^{c}$ & - \\
\hline $\mathrm{CH}_{2}$ & $\mathrm{C}_{3}$ & $220 \pm 30$ & $32 \cdot 2 \pm I^{\cdot} 4^{c}$ & $89 \cdot 2 \pm 3 \cdot 5^{c}$ \\
\hline $\mathrm{CH}_{2}$ & $\mathrm{C}_{4}$ & & $32 \cdot 7 \pm I \cdot 2^{c}$ & $87.7 \pm 1 \cdot 5^{c}$ \\
\hline $\mathrm{CH}_{2}$ & $\mathrm{C}_{5}$ & & $33^{\circ} \circ \pm 2 \cdot I^{\mathrm{c}}$ & - \\
\hline $\mathrm{CH}_{2}$ & C6 & & $34 \cdot 3 \pm \mathrm{r} \cdot 8^{\mathrm{c}}$ & - \\
\hline $\mathrm{CH}_{2}$ & $\mathrm{C}_{7}$ & & - & - \\
\hline $\mathrm{CH}_{2}$ & $\mathrm{C} 8$ & & $36 \cdot 3 \pm I \cdot 6^{c}$ & $106 \cdot 7 \pm 2.9^{c}$ \\
\hline $\mathrm{CH}_{2}$ & $\mathrm{C}_{9}$ & $530 \pm 10 f$ & $37 \cdot 7 \pm I \cdot 7^{\mathrm{c}}$ & $139 \cdot 6 \pm 5 \cdot 7^{\mathrm{c}}$ \\
\hline $\mathrm{CH}_{2}$ & $\mathrm{C}_{10}$ & & - & - \\
\hline $\mathrm{CH}_{2}$ & $\mathrm{C}_{11}$ & & - & - \\
\hline $\mathrm{CH}_{2}$ & $\mathrm{C}_{12}$ & & $54.5 \pm 3^{\cdot} 6^{c}$ & $232 \cdot 4 \pm 7 \cdot 1^{\mathrm{c}}$ \\
\hline $\mathrm{CH}_{2}$ & $\mathrm{C}_{13}$ & $\perp$ & 一 & - \\
\hline $\mathrm{CH}_{2}$ & $\mathrm{C}_{14}$ & $1130 \pm 180$ & $95.4 \pm 3 \cdot 5^{c}$ & $410 \pm 15^{\cdot} 8^{c}$ \\
\hline $\mathrm{CH}_{2}$ & $\mathrm{C}_{15}$ & $1810 \pm 80$ & $138 \cdot 5 \pm 3 \cdot 7^{\mathrm{c}}$ & - \\
\hline $\mathrm{CH}_{3}$ & $\mathrm{C}_{16} 6$ & $5010 \pm 370$ & $275^{*, d}$ & 一 \\
\hline
\end{tabular}


microviscosity) refers to membranes in general and is independent of the specific technique employed. This is also illustrated by fluorescence spectroscopy, where it has been realized only recently that the interpretation of fluorescence depolarization measurements exclusively in terms of microviscosity is incorrect, but that the fluorescence anisotropy is equally dependent on the ordering of the fluorescent probe in the membrane (Heyn, I979; Jähnig, I979). Thus the correct evaluation of fluorescence anisotropy data leads to an order parameter as well as to correlation times.

The problem of fatty acyl motions in phospholipid bilayers has been investigated with ${ }^{2} \mathrm{H}$-nmr using selectively deuterated $\mathrm{I}, 2$-dipalmitoylsn-glycero-3-phosphocholine (Brown, Seelig \& Häberlen, 1979), DPPC with perdeuterated fatty acyl chains (Davis, 1979) or selectively deuterated stearic acids intercalated in egg lecithin vesicles (Stockton et al. 1976). Table I provides a summary of ${ }^{2} \mathrm{H}$ spin-lattice relaxation times, $T_{1}$, of selectively deuterated DPPC in unsonicated lipid bilayers and in organic solution. The data are compared with ${ }^{13} \mathrm{C}-\mathrm{nmr}$ relaxation times which constitute probably the most extensive other set of information on phospholipid mobility in membranes (Lee et al., I 976). The ${ }^{13} \mathrm{C}$-nmr relaxation times are about one order of magnitude larger than the corresponding deuterium relaxation times which can be traced back to the different relaxation mechanisms involved. The deuterium nucleus relaxes via quadrupole relaxation which is especially fast because of the large quadrupole moment of the deuterium nucleus. By contrast, the dominant relaxation mode for ${ }^{13} \mathrm{C}-\mathrm{nmr}$ is provided by intramolecular proton carbon dipolar interactions. More interesting than the absolute values of the relaxation times is the dependence of $T_{1}$ on the segment position. Inspection of Table I reveals that the same trend is observed by both methods. (I) The glycerol backbone has the shortest relaxation time which means that this part of the molecule is moving most slowly. On the other hand, the longest relaxation times are observed for the methyl groups at either end of the phospholipid molecule, indicating very fast internal rotations of the methyl rotors. (2) The relaxation times of the two methylene segments in the polar head group $\left(C_{\alpha}\right.$ and $\left.C_{\beta}\right)$ are rather similar. Even closer agreement has been obtained for the same segments in other polar groups such as phosphoethanolamine and phosphoserine. (Browning \& Seelig, unpublished work) and is indicative of a strongly correlated motion of these two segments. (3) The relaxation times of the fatty acyl chains appear 


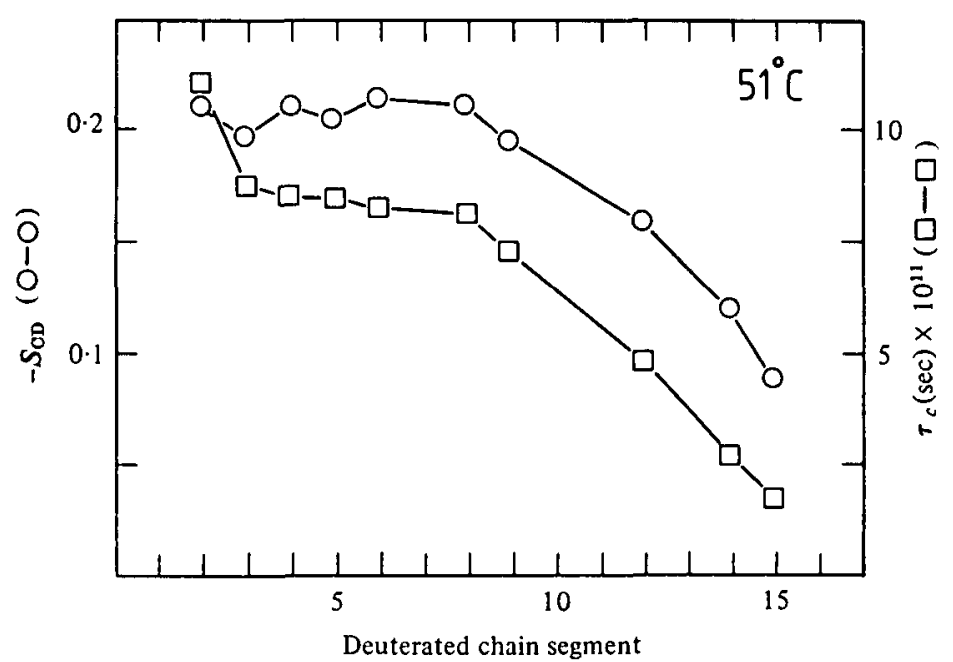

Fig. Io. Comparison of the rotational correlation times ( $\square$ ) determined from the $T_{1}$ data and the deuterium order parameters $(O)$ as a function of segment position. Reproduced with permission from Brown, Seelig \& Häberlen (1980).

to be more or less constant over the first half of these chains $\left(\mathrm{C}_{3}-\mathrm{C}_{9}\right)$ followed by an increase in the central region of the bilayer. Again the ${ }^{13} \mathrm{C}$-relaxation time profiles parallels that of ${ }^{2} \mathrm{H}-\mathrm{nm}$ to a large extent. All relaxation times $T_{1}$ increase with increasing temperature, which implies that the correlation time $\tau_{c}$ of the segment reorientation falls in the so-called short correlation time regime with $\omega_{0}^{2} \tau_{c}^{2} \ll \mathrm{I}$, where $\omega_{0}$ is the measuring frequency in $\mathrm{rad} / \mathrm{sec}$. Assuming a single type of segment reorientation, i.e. a motion sufficiently characterized by a single correlation time $\tau_{c}$, the following expression holds for the short correlation time limit (Seelig, I977; Davis, Jeffrey \& Bloom, 1978; Brown, Seelig \& Häberlen, 1979).

$$
\mathrm{I} / T_{1}=\frac{3}{8}\left(\frac{e^{2} q Q}{\hbar}\right)^{2}\left(1-S_{\mathrm{cD}}^{2}\right) \tau_{c} .
$$

In principle, the deuterium $T_{1}$ relaxation time depends on both the ordering $\left(S_{\mathrm{CD}}\right)$ and rate of motion $\left(\tau_{c}\right)$. However, the order parameters, $S_{\mathrm{CD}}$, for the fatty acyl chain segments are between zero and $-0 \cdot 2$. Consequently, the order correction in the last equation tends to be less than $20 \%$. In Fig. Io we have compared the rotational correlation times derived using equation (5) to the deuterium order parameters as a function of the labelled segment position. The shapes of the correlation 
time and order profile are similar, with the correlation times ranging from about $8 \times 10^{-11} \mathrm{sec}$ for the plateau region to about $3 \times 10^{-11} \mathrm{sec}$ for the C-I 5 methylene segment. The correlation time $\tau_{c}$ of a spherical molecule is related to the microviscosity $\eta$ of the liquid according to

$$
\tau_{c}=\frac{4 \pi}{3} \frac{\eta r^{3}}{k T}=\frac{\eta V}{k T} .
$$

$r$ and $V$ are radius and volume of the sphere, respectively, and $k T$ is the thermal energy. The derivation of equation (6) is based on a hydrodynamic approach which treats the bilayer as a continuum. The experimental data suggest that this may not necessarily be correct. Using an effective volume of $27 \cdot 0 \AA^{3}$ for the $\mathrm{CH}_{2}$ group (Tardieu et al. 1973) one calculates a microviscosity of $\eta \simeq 13 \mathrm{cP}$ (at $5{ }^{\circ}{ }^{\circ} \mathrm{C}$ ) for the rotational friction in the plateau region of the DPPC bilayer. The rotational microviscosity estimated from ${ }^{13} \mathrm{C}-\mathrm{nmr}$ relaxation times is $c .50 \mathrm{cP}$ (Lee et al. 1976). Other methods such as spin label electron paramagnetic resonance or fluorescence depolarization spectroscopy provide values which range from I $\mathrm{cP}$ (Dix, Kivelson \& Diamond, 1978) to $c$. $100 \mathrm{cP}$ (Hare \& Lussan, 1977). The differences can probably be attributed to the presence of 'probe effects', i.e. the different rotational slip or effective friction coefficient associated with the individual 'probe' molecules, and illustrate the difficulties inherent in the concept microviscosity. Again different results are obtained when bacteriohodop$\sin$ is used as a probe to measure membrane viscosity. Depending on the protein-to-lipid ratio, viscosities ranging from about 3-50 $\mathrm{P}$ are estimated (Cherry et al., 1977; Cherry, 1979). This result can be interpreted to suggest that (i) small probes are more sensitive to the local hydrocarbon chain motions than large probes and (ii) the membrane viscosity is modified by the presence of proteins.

\section{LIPID-PROTEIN INTERACTION}

In biological membranes the number of lipid molecules in immediate contact with membrane proteins is quite large due to the rather high protein-to-lipid ratio $(P / L>\mathrm{I} \mathrm{wt} / \mathrm{wt})$ and some molecular parameters of the lipid-protein interface must change compared to the protein-free membrane. The present section will concentrate on some physicalchemical aspects of lipid-protein interaction; the biochemical problem of regulation of membrane enzymes by lipids is distinctly more complex 


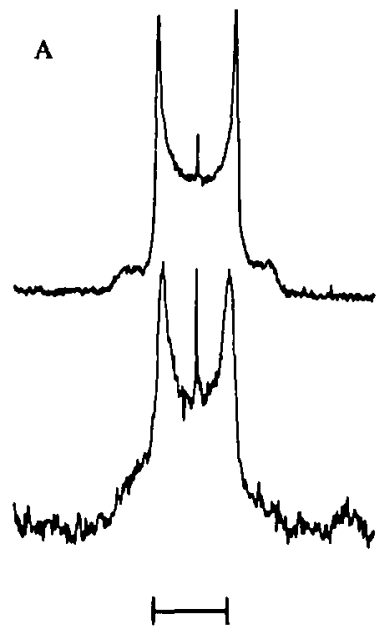

$20 \mathrm{kHz}$

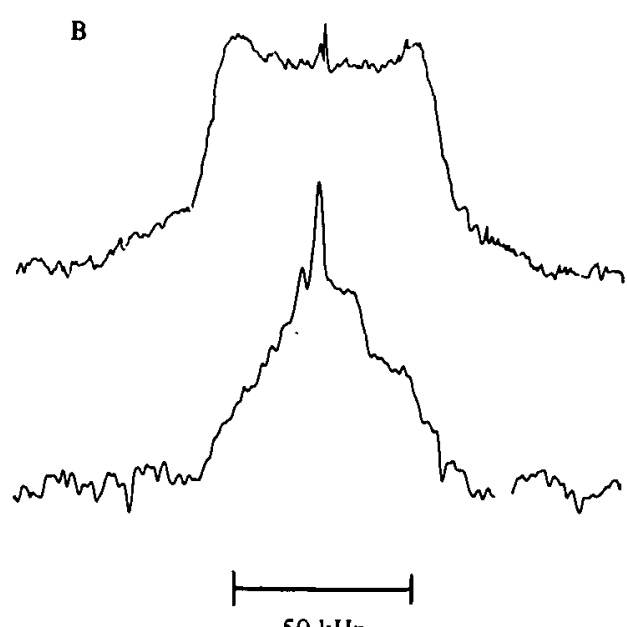

$50 \mathrm{kHz}$

Fig. II. ${ }^{8} \mathrm{H}-\mathrm{nmr}$ spectra (at $46 \cdot \mathrm{I} \mathrm{MHz}$ ) of reconstituted functional sarcoplasmic reticulum. The natural lipids are exchanged to the extent of $99 \%$ with I,2-dielaidoyl-sn-glycerol-3-phosphocholine (DEPC). At least $90 \%$ of the DEPC is deuterated in both chains at the 9, 10 position, i.e. at the transdouble bond. The phase transition of DEPC occurs at about $10^{\circ} \mathrm{C}$.

(A) Measurements above the phase transition temperature. Measuring temperature $25^{\circ} \mathrm{C}$. The upper spectrum corresponds to pure $1,2-\mathrm{di}[9,10-$ ${ }^{2} \mathrm{~Hz}$ ]elaidoyl-sn-glycero-3-phosphocholine and the quadrupole splitting is $2 \mathrm{I}^{\cdot} 5$ $\mathrm{kHz}$. The lower spectrum is due to be reconstituted sarcoplasmic reticulum exchanged with the same lipid. The quadrupole splitting is reduced to 18.8 kHz.

(B) Measurement below the phase transition temperature. Measuring temperature $4^{\circ} \mathrm{C}$. Upper spectrum: pure DEPC. Lower spectrum: reconsituated sarcoplasmic reticulum (Seelig et al., 1980).

and beyond the scope of this article (for a review see Sandermann, 1978).

Some of the earliest evidence for the physical interaction of lipids with proteins has come from spin label electron paramagnetic resonance (epr). In brief, spin-label epr spectra of a variety of reconstituted lipidprotein systems have revealed the existence of two different types of environments. One spectral component is characteristic of a normal fluid lipid bilayer, whereas the second spectral component is ascribed to a more immobilized spin label. The second component is observed only in the presence of protein and grows in proportion to the protein content in the membrane. From this evidence it has been concluded that the more immobilized signal is due to lipid molecules in immediate contact with the hydrophobic surface of the membrane proteins (Jost 
et al. 1973; Hesketh et al. 1976; for a review see Jost \& Griffith, I980).

Electron paramagnetic resonance is characterized by a relatively short time-scale. If the problem of lipid-protein interaction is investigated on the much lower time scale of ${ }^{2} \mathrm{H}-\mathrm{nmr}$ the results appear to be different at first sight. Two approaches have been employed. One possibility is the purification and delipidation of membrane bound proteins followed by reconstitution with selectively deuterated lipids, the other possibility is the biosynthetic incorporation of deuterated fatty acids or other deuterated substrates into biological membranes. In the latter case the intact biological membrane is compared with aqueous bilayer dispersions formed from the extracted lipids (Gally et al. I980). A variety of membrane proteins has now been reconstituted in functional form into a matrix of deuterated lipids, most notably cytochrome $c$ oxidase (Oldfield et al. 1978b; Seelig \& Seelig, 1978; Kang et al. 1979) and $\mathrm{Ca}^{2+}$-dependent ATPase (Rice et al. 1979; Seelig et al., I980). Typical ${ }^{2} \mathrm{H}-\mathrm{nmr}$ spectra of reconstituted functional sarcoplasmic reticulum membrane vesicles exchanged to $99 \%$ with a single lipid environment are shown in Fig. II. The lipid used in this study is I,2-di $\left[3\right.$, IO- $\left.^{2} \mathrm{~Hz}\right]$ eloidoyl $\mathrm{I}_{2}$-sn-glycero-3-phosphocholine (DEPC), which accounts for $c .90 \%$ of the total lipid, the rest being non-deuterated DEPC. Above the phase transition temperature of DEPC ( $10{ }^{\circ} \mathrm{C}$ ) the spectra are characteristic of a fluid lipid bilayer with a single quadrupole splitting. Indeed, the general observation in all ${ }^{2} \mathrm{H}-\mathrm{nmr}$ reconstitution studies reported so far is that only one homogeneous lipid environment is present above $T_{c}$ even when a substantial amount of protein is present. The ${ }^{2} \mathrm{H}-\mathrm{nmr}$ experiments give no indication for a strong, long-lived interaction between the membrane protein and the lipid. Instead, the data can be explained by a relatively rapid exchange between those lipids in contact with the protein and those further away from it. This exchange must be fast on the ${ }^{2} \mathrm{H}-\mathrm{nmr}$ time scale (exchange rate $>10^{4} \mathrm{~Hz}$ ) in order to produce a single component ${ }^{2} \mathrm{H}-\mathrm{nmr}$ spectrum but slow compared to the epr-time scale (exchange rate $<10^{7} \mathrm{~Hz}$ ) in order to account for the two-component spin label spectrum. Thus the simplest explanation for the differences between epr and ${ }^{2} \mathrm{H}-\mathrm{nmr}$ reconstitution studies would be a time-scale effect (cf. Jost \& Griffith, I980). On the other hand, spin-label experiments have been reported in which spin-labelled fatty acids have been covalently attached to a membrane protein, rhodopsin, and no appreciable perturbation of the fatty acyl 


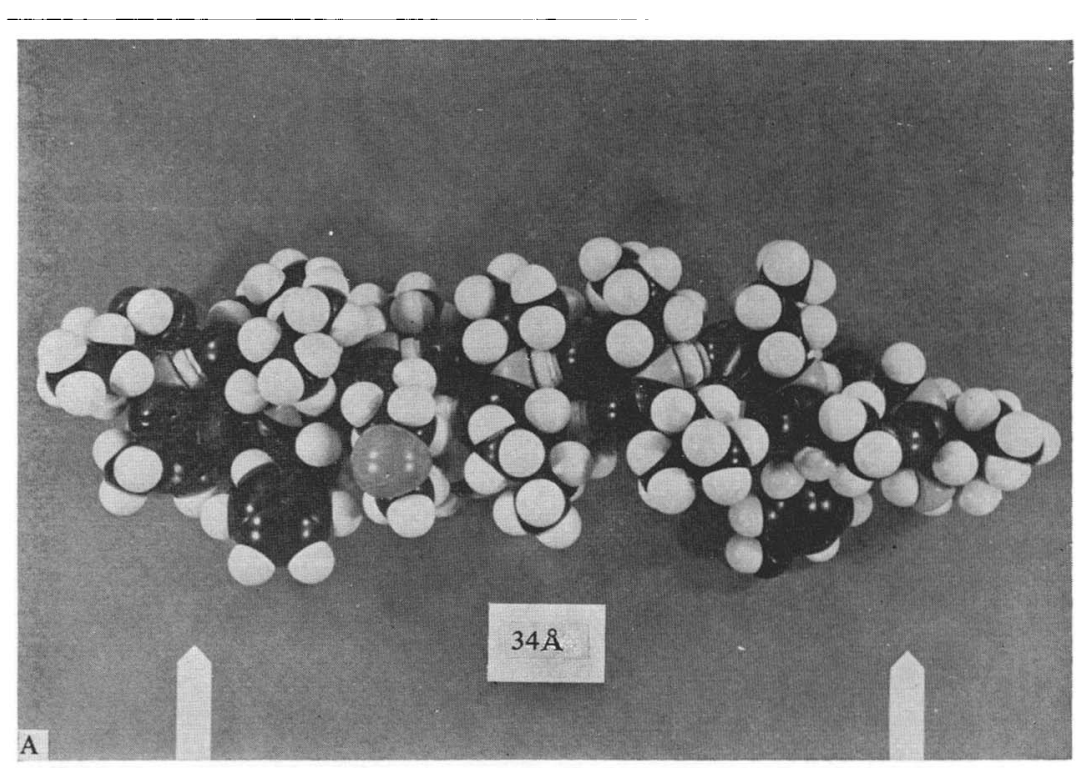

Fig. $12 \mathrm{~A}$

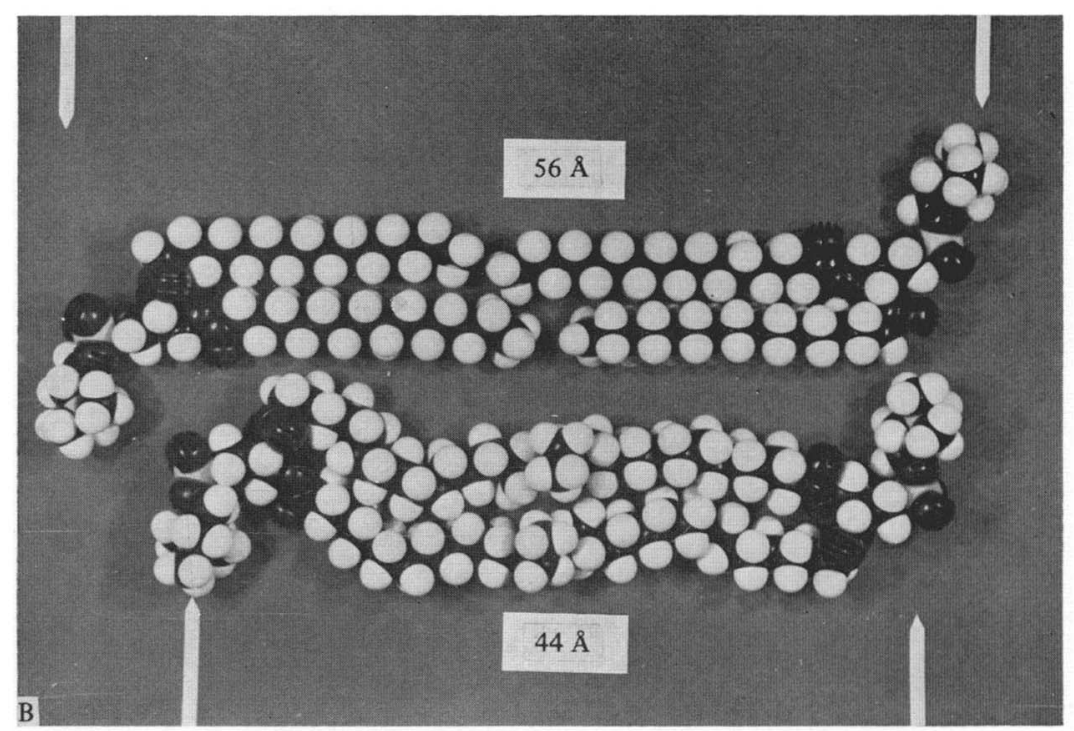

Fig. I2B

For legend see over. 


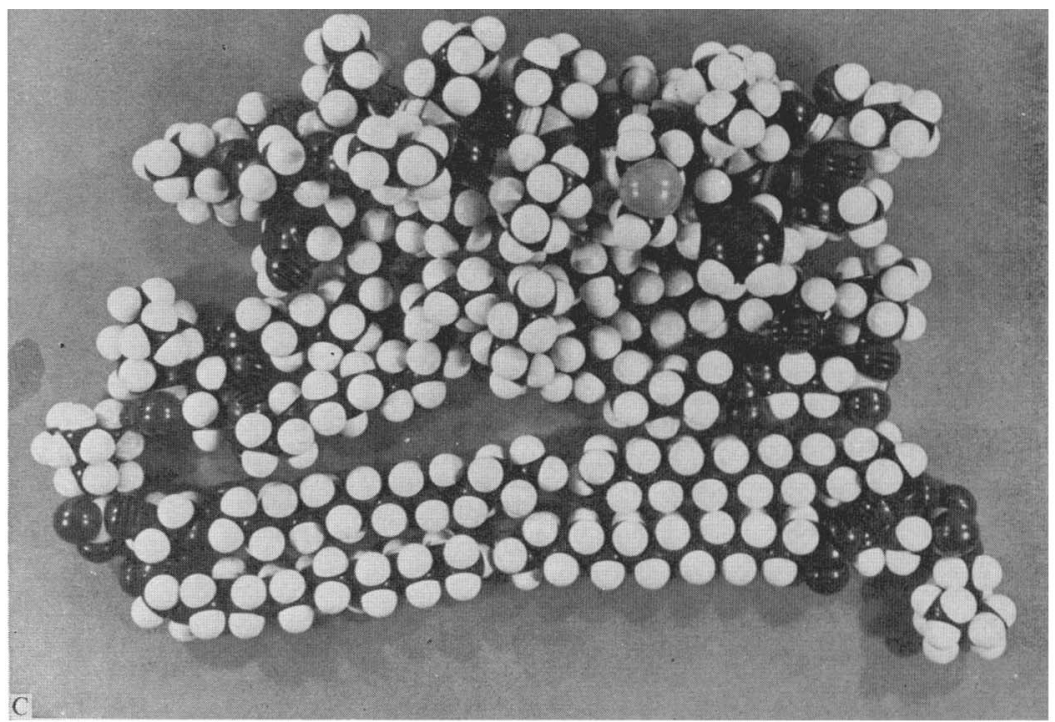

Fig. I2 C

Fig. I 2. Molecular model of a membrane protein in a lipid bilayer.

(A) The hydrophobic sequence (amino acid residues 73-95) of glycophorin $\mathrm{A}$ in the $\alpha$-helical configuration.

(B) Molecular models of a bilayer composed of I,2-dipalmitoyl-sn-glycero3-phosphocholine (DPPC). The upper model shows the molecules in the extended all-trans conformation. The lower model corresponds to the liquidcrystalline state and each fatty acyl chain contains 4-5 gauche conformations. The indicated dimensions correspond to the experimental values determined by neutron diffraction. It may be noted that the glycerol backbone is perpendicular to the bilayer surface as is the $s n$ - I-palmitic acyl chain, whereas the $s n-2$ chain is bent. The polar head groups are parallel to the surface of the membrane in agreement with ${ }^{2} \mathrm{H}$ - and ${ }^{31} \mathrm{P}-\mathrm{nmr}$ and neutron diffraction results.

(C) The hydrophobic sequence of glycophorin A in a bilayer of DPPC. For a comparison two DPPC molecules in the all-trans conformation are also shown. 
chains was found in the natural disc membrane (Davoust et al. I 980 , and references cited therein). The same probe linked to rhodopsin in eggyolk lecithin-rhodopsin vesicles sees, however, two environments. The explanation is proposed that the immobilized component reflects proteinprotein contact and therefore is due to labelled lipid chains trapped between clustered proteins (cf. also Chapman et al. 1979, for a review).

${ }^{2} \mathrm{H}-\mathrm{nmr}$ is generally more sensitive to structural and dynamic changes than spin label epr, and even though the method does not detect a specific boundary layer of lipids, a closer inspection of the ${ }^{2} \mathrm{H}-\mathrm{nmr}$ spectra of reconstituted membranes reveals three interesting features. (i) Membranes with protein exhibit a small, but finite decrease (10-25\%) in the quadrupole splitting compared to pure lipid samples. (ii) The deuterium $T_{1}$-relaxation times are shorter by about $20-30 \%$ in reconstituted membranes. (iii) The apparent linewidth of the ${ }^{2} \mathrm{H}$ - and ${ }^{31} \mathrm{P}-\mathrm{nmr}$ spectra increases in protein containing samples (cf. Fig. I I A).

The reduction in the deuterium quadrupole splitting can be ascribed to a disordering effect of the protein interface. In most membrane models presented in the literature the membrane proteins are drawn as smooth cylinders or rotational ellipsoids. This is probably not very realistic. Even if the protein-backbone is arranged in an $\alpha$-helical configuration, the protrusion of amino acid side-chains will lead to an uneven shape of the protein surface. This is illustrated in Fig. I2A with a molecular model of glycophorin. Glycophorin is an intrinsic membrane protein the sequence of which has been determined (Furthmayr, 1977). Fig. 12 A represents a molecular model of the hydrophobic part of this sequence which is supposed to span the bilayer membrane. Following the contours of the model the roughness of the protein surface becomes obvious even in its two-dimensional projection. The lipids, since they are flexible molecules, will follow the shape of the protein to a certain extent creating a closely packed hydrophobic barrier. Though already disordered in the pure lipid bilayer, the fatty acyl chains become even more distorted by the contact with the hydrophobic site. This is shown schematically in Fig. $12 \mathrm{C}$, where the hydrocarbon chains are twisted more or less dramat cally in order to fill the glycophorin surface. The reduction of the deuterium order parameter by the membrane protein is quantitatively equivalent to a rise in temperature of the pure lipid bilayer by $20-30{ }^{\circ} \mathrm{C}$. The spatial disorder of the hydrocarbon chains may further be augmented by density fluctua- 


\section{T AB LE 2. Deuterium $T_{1}$-relaxation times (at $46 \cdot 03 \mathrm{MHz}$ ) of reconstituted membranes}

\begin{tabular}{cccc}
\hline & & \multicolumn{2}{c}{$T_{1}$ (msec) } \\
\cline { 3 - 4 } System & $\begin{array}{c}\text { Temperature } \\
\left({ }^{\circ} \mathrm{C}\right)\end{array}$ & $\begin{array}{c}\text { Reconstituted } \\
\text { membrane }\end{array}$ & $\begin{array}{c}\text { Pure lipid } \\
\text { bilayer }\end{array}$ \\
\hline Cytochrome $c$ oxidaset, & 5 & 6.7 & 7.9 \\
lipid-to-protein ratio & 15 & 8.8 & 10.9 \\
$\sim 0.75$ (wt./wt.) & 28 & 11.9 & 15.5 \\
sarcoplasmic reticulum $\neq, \mathrm{b}$ & 24 & 11.1 & 13.9 \\
lipid-to-protein ratio & & & \\
$\sim 0.33$ (wt./wt.) & & & \\
\hline \hline
\end{tabular}

$\dagger$ Reconstituted with I,2-di[9,10-2 $\mathrm{Hz}]$ oleoyl-sn-glycero-3-phosphacholine.

$\ddagger$ The lipid employed is 1,2 -di $\left[9,10-{ }^{2} \mathrm{~Hz}\right]$ elaidoyl-sn-glycero- 3 -phosphocholine.

- L. Tamm \& J. Seelig (unpublished results).

b Fleischer, Hymel \& Seelig (1980).

tions on the protein surface itself. It has been suggested that membrane proteins have a 'fluid-like' outer region which provides an approximate fluid mechanical match with the liquid crystalline phospholipid membrane (Bloom, I979).

The observed disordering effect does not necessarily imply an increase in the configurational space available to the fatty acyl chains. In fact, it appears to be more probable that the total number of chain configurations is reduced, while the statistical probability of more distorted chain conformations increases at the same time.

From the increase in spatial disorder it cannot be concluded that the membrane is also more fluid. On the contrary, deuterium $T_{1}$ relaxation time measurements suggest a decrease in the rate of segment reorientation in the presence of protein. Such deuterium $T_{1}$ measurements have been performed with cytochrome $c$ oxidase and reconstituted sarcoplasmic reticulum and some representative results are summarized in Table 2. The addition of protein decreases the relaxation time in both cases. Above $T_{c}$ the motion still falls into the fast correlation time regime as evidenced by the longer $T_{1}$ relaxation times at higher temperatures. According to equations (5) and (6), shorter $T_{1}$ relaxation times are therefore equivalent to an increase in the microviscosity. This conclusion is supported by ${ }^{13} \mathrm{C}-\mathrm{nmr}$ experiments with reconstituted sarcoplasmic reticulum (Stoffel, Zierenberg \& Scheefers, I977). The $T_{1}$ relaxation rates of ${ }^{13} \mathrm{C}$-labelled lipids decrease continuously with increasing protein concentration in the membrane. However, an unam- 
biguous quantitative analysis of these changes is not possible. In particular, it is difficult to see how the fast motions of the hydrocarbon chains can be related to the slower motions of the proteins.

The disordering effect of membrane proteins on the lipid fatty acyl chains could also provide an explanation for some thermodynamic peculiarities of lipid-protein systems. Aqueous dispersions of synthetic phospholipids are characterized by a relatively sharp gel-to-liquid crystal phase transition with a well-defined transition temperature $T_{c}$ and a transition enthalpy $\Delta H$ (Chapman, 1975). Upon addition of protein the transition gradually broadens and the transition enthalpy decreases. At high protein concentrations the phase transition may not be detectable at all (Curatolo et al. 1977; Chapman et al. 1977; van Zoelen et al. 1978; Mombers et al. 1979). The broadening of the phase transition has also been confirmed by other methods as, for example, fluorescence spectroscopy (Gomez-Fernandez et al. 1979; Heyn, 1979). The most plausible explanation for this broadening is a loss of cooperativity due to lattice defects. Below the transition temperature $T_{c}$ the fatty acyl chains of a pure lipid bilayer are arranged in a quasicrystalline lattice with the chains more or less in the extended all-trans conformation. Heating the system above $T_{c}$ destroys the lattice order which is accompanied by the consumption of energy. By contrast, the lipids in protein-containing membranes are forced to adopt a more irregular conformation. The protrusions from the protein backbone prohibit a perfect regular packing and the more disordered conformations of the liquid state are already pre-formed below $T_{c}$.

Experimental support for this supposition could come from the direct observation of lipids below the gel-to-liquid crystal transition temperature. ${ }^{2} \mathrm{H}$-nmr gel-state spectra have been reported now for Acholeplasma laidlawii (Smith et al. 1979; Rance et al. 1980), Escherichia coli (Davis et al. 1979; Kang, Gutowsky \& Oldfield, 1979; Nichol et al. 1980), and for a variety of reconstituted membranes (Rice et al. 1979, and references cited therein). Gel-state spectra of reconstituted sarcoplasmic reticulum and pure phospholipid bilayers at the same temperature are shown in Fig. I I B. The interpretation of such spectra is more complex, since they can no longer be described by a single order parameter. At present it is unclear if the spectral shape results from slow-motion effects (Meirovitch \& Freed, 1979) or from a distribution of order parameters. If the assumption of an order parameter distribution should turn out to be the correct quantitative approach, then the spectrum of recon- 
stituted sarcoplasmic reticulum certainly comprises a larger distribution of quadrupole splittings than that of the pure lipid. This, in term, would imply a larger spectrum of chain conformations in the reconstituted membrane (cf. also Pink \& Zuckermann, 1980).

The effect of proteins on the lipid structure may be compared with the incorporation of cholesterol. With regard to the thermodynamic properties, cholesterol also acts as an 'impurity', i.e. the phase transition of the pure lipid bilayer is broadened and the transition enthalpy is reduced and eventually eliminated when increasing amounts of cholesterol are added (cf. Chapman, 1975; Mabrey, Mateo \& Sturtevant, 1978, and references cited therein). Likewise, ${ }^{2} \mathrm{H}-\mathrm{nmr}$ spectra of cholesterol-phospholipid mixtures in the concentration range of about $0-50$ mole $\%$ are characteristic of a single, homogeneous phase, at least at temperatures above $T_{c}$ (Haberkorn et al. 1977; Jacobs \& Oldfield, 1979). However, compared to the disordering effect of proteins cholesterol induces a dramatic ordering effect in the bilayer structure. At a phospholipid/cholesterol I/I molar ratio the molecular order parameter of selectively labelled lipids has almost doubled compared to the cholesterol-free bilayer (Gally, Seelig, \& Seelig, 1976; Stockton \& Smith, 1976; Haberkorn et al. 1977; Oldfield et al. 1978a; Jacobs \& Oldfield, I979). The different influence of cholesterol compared to membrane proteins is understandable if one takes into account the different shapes of the two components. Cholesterol is a flat, rod-like molecule with a rigid molecular frame. The presence of this molecule in the membrane therefore drastically restricts the trans-gauche isomerizations and flexing motions of the hydrocarbon chains, thus explaining the increase in the order parameter.

As a general conclusion it follows that in both cases investigated the lipids are mainly influenced by the shape of the 'guest' molecules, i.e. protein or cholesterol. The available data provide no evidence for thermodynamically stable complexes of well-defined stoichiometry.

\section{THE POLAR HEAD GROUPS: IONIC INTERACTIONS}

From the biological point of view the specific recognition of phospholipid polar groups by membrane proteins appears to be most intriguing. Unfortunately, little is known about possible head-group specificities of membrane-bound enzymes (cf. Sandermann, I978). Physical-chemical studies on phospholipid head groups, though quite numerous, have 
also not been very revealing (for a review see Hauser \& Phillips, 1979). It is in this area of head-group structure and head-group interactions where methods such as ${ }^{2} \mathrm{H}-\mathrm{nmr}$ and neutron diffraction could become very powerful analytical tools. A few promising steps in this direction have already been made but the present section must remain more an outlook than a definitive review.

The synthesis of head-group deuterated lipids is more demanding than the deuteration of the fatty acyl chains. Complete sets of head-group deuterated derivatives are now available for $s n$-3-phosphatidylcholine (Gally, Niederberger \& Seelig, 1975), sn-2-phosphatidylcholine (Seelig et al. 1980), phosphatidylethanolamine (Seelig \& Gally, 1976), phosphatidylserine (Browning \& Seelig, 1980) and phosphatidylglycerol (Wohlgemuth et al. 1980). In addition, a glycolipid has been selectively deuterated in the sugar moiety (Skarjune \& Oldfield, 1979a).

As a first result, head-group labelled lipids in combination with neutron diffraction methods have helped to decide the controversial issue of head-group orientation. For bilayers of phosphatidylcholine it could be demonstrated that the average orientation of the phosphocholine dipole is nearly parallel to the membrane surface, in the gel state as well as in the liquid crystalline state (Büldt et al. 1978, 1979). The same head-group orientation has been established for bilayers of phosphatidylethanolamine (Büldt \& Seelig, 1980). In single crystals of phosphatidylethanolamine (Hitchcock et al. 1974) and phosphatidylcholine (Pearson \& Pascher, 1979) the head group is also parallel to the bilayer surface. The alignment of other head groups is not known at present but such data should become available soon from neutron diffraction measurements.

Comprehensive ${ }^{2} \mathrm{H}$ - and ${ }^{31} \mathrm{P}-\mathrm{nmr}$ head-group studies have been reported for phosphocholine, phosphoethanolamine, phosphoserine and phosphoglycerol. A comparison of the corresponding quadrupole splittings, $\Delta \nu_{Q}$, and chemical shielding anisotropies, $\Delta \sigma$, is given in Table 3. The nomenclature $\alpha, \beta, \gamma$ is employed for the deuterated head-group segments, the $\alpha$-segment being closest to the phosphate group, the $\gamma$-segment being farthest away from it. The following conclusions can be derived from these investigations. (i) Each head group has its own characteristic set of spectroscopic parameters which is not influenced much by the rest of the molecule. Thus almost identical spectral patterns are obtained for I,2-dimyristoyl-/1,2-dioleoyl-snglycero-3-phosphoserine and $s n-3-/ s n-2$ phosphatidylcholine, respec- 
T A BLE 3. Comparison of the chemical shielding anisotropy, $\Delta \sigma$, and the deuterium quadrupole splittings, $\Delta \nu$, of phospholipid head groups $\dagger$

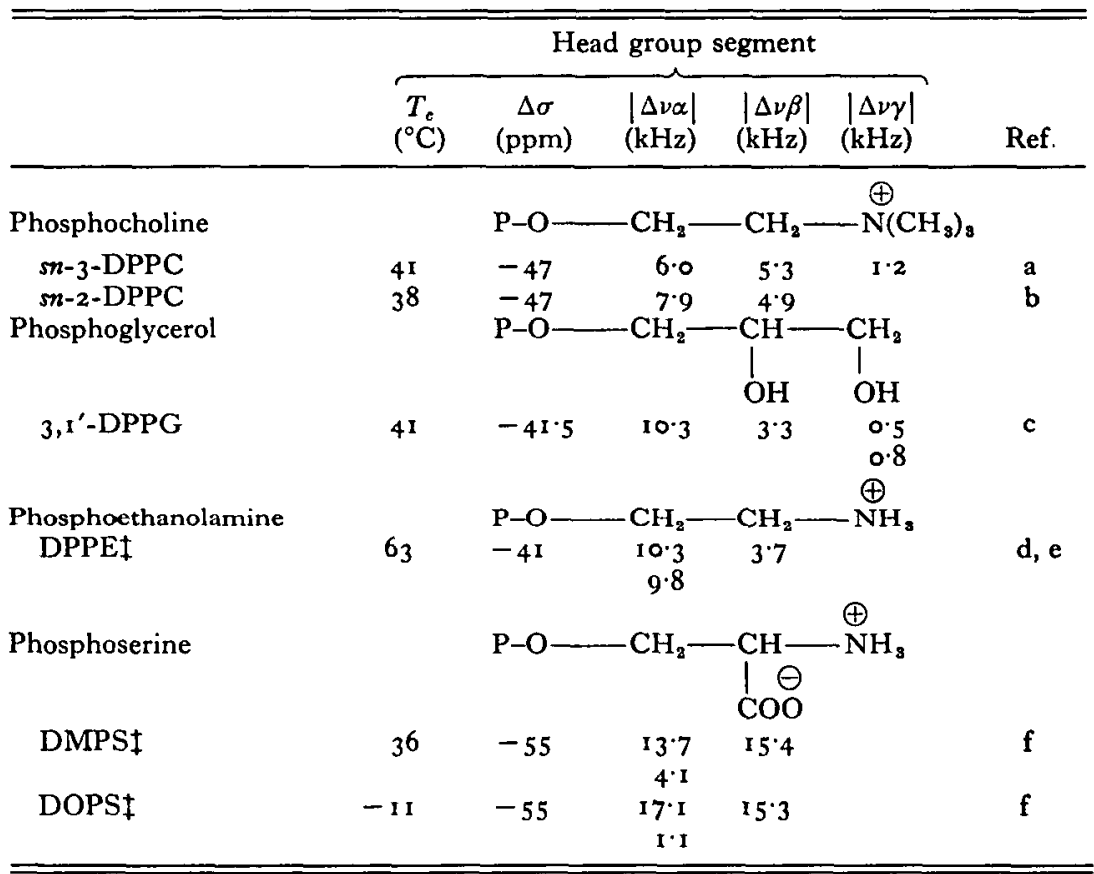

$\dagger$ Data are compared at corresponding temperatures, i.e. about $5{ }^{\circ} \mathrm{C}$ above the respective gel-to-liquid crystal transition temperature.

t Two quadrupole splittings are observed for the $\alpha-\mathrm{CD}_{2}$ segment which presumably must be assigned to the two deuterons:

$s n-2-D P P C$

sn-3-DPPC

3,1'-DPPG 1,2-dipalmitoyl-sn-glycero-3-phospho-1'-glycerol

DPPE 1,2-dipalmitoyl-sn-glycero-3-phosphoethanolamine

DMPS I,2-dimyristoyl-sn-glycero-3-phosphoserine

DOPS 1,2-dioleoyl-sn-glycero-3-phosphoserine
(a) Gally et al. (1975).
(b) Seelig et al. (1980).
(c) Wohlgemuth et al. (1980).
(d) Seelig \& Gally (1976).
(e) H. Akutsu \& J. Seelig (unpublished results).
(f) Browning \& Seelig (1980).

tively. (ii) In spite of some distinct differences in the spectroscopic properties, the data suggest similar head-group structures and motions for phosphocholine, phosphoethanolamine and phosphoglycerol. The $\Delta \nu_{Q}$ and $\Delta \sigma$ values of the phosphoserine head group are definitely larger. 
(iii) All head groups exhibit restricted internal rotations. A completely rigid head group appears to be inconsistent with the spectroscopic data as is the other extreme, i.e. a head group with unhindered bond rotations (cf. also Hauser et al. 1980). Motional models which are in agreement with the $\mathrm{X}$-ray diffraction structure analysis have been proposed (cf. Seelig et al., I 977; Skarjune \& Oldfield, I979b). The rate of rotation of the phosphocholine dipole has been determined from dielectric measurements and a relaxation time of $2 \cdot 3 \mathrm{nsec}$ at $50^{\circ} \mathrm{C}$ in fully hydrated samples was obtained (Shepherd \& Büldt, 1978). This is about an order of magnitude slower than the relaxation rate of zwitterionic dipoles of comparable molecular weight in aqueous solution. (iv) In bilayers of phosphatidylcholine or phosphatidylethanolamine the polar groups are little influenced by the addition of cholesterol (Brown $\&$ Seelig, 1978). From neutron diffraction studies it is known that cholesterol is anchored with its hydroxyl group in the vicinity of the fatty acid carbonyls, i.e. below the polar group (Worcester \& Franks, 1976). As far as these two head groups are concerned cholesterol simply acts as a spacer molecule. (v) The choline and ethanolamine head groups are sensitive to cations. Significant changes in the quadrupole splittings of the $\alpha$ and $\beta$ head group segments are induced by di- and trivalent cations. Monovalent cations and various anions have only little effect (Brown \& Seelig, I977; H. Akustu \& J. Seelig, unpublished results). Fig. I3 contains representative results for the $\alpha-\mathrm{CD}_{2}$ group of bilayers of 1,2 -dipalmitoyl-sn-glycero-3-phosphocholine. Chloroform has no effect on this segment while addition of ions decrease the absolute value of the quadrupole splitting. The detailed analysis of such binding data may eventually lead to a quantitative understanding of the mode of interaction of ions with an electrically neutral membrane surface.

${ }^{2} \mathrm{H}$ - and ${ }^{31} \mathrm{P}-\mathrm{nmr}$ studies specifically directed towards an elucidation of polar head-group interactions with proteins are only in their beginning. Methyl deuterated choline has been incorporated biosynthetically into rat liver mitochondria and mouse fibroblasts (Oldfield, Meadows \& Glaser, 1976). It could be demonstrated that it is technically feasible to measure ${ }^{2} \mathrm{H}-\mathrm{nmr}$ quadrupole splittings even at very low concentrations of deuterated material. Under these conditions the natural abundance of deuterium in water may interfere with the head-group signal and the use of deuterium-depleted water is recommended. A second example is the development of $E$. coli mutants which are defective in the synthesis of glycerol. If the glycerol auxotrophs are grown on specifically deutera- 


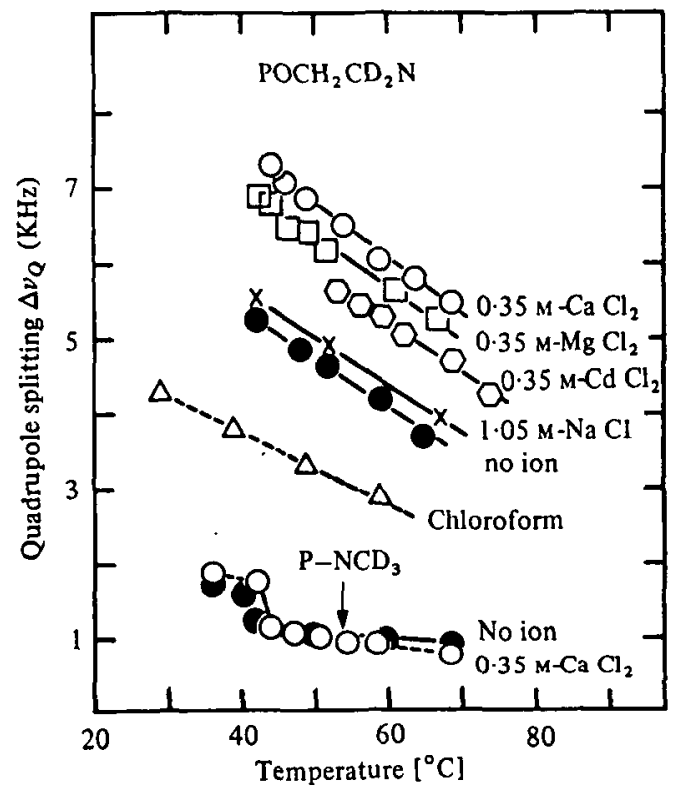

Fig. 13. Ion binding to bilayers of I,2-dipalmitoyl-sn-glycero-3-phosphocholine deuterated at the $\alpha$-segment of the choline moiety (A. Akutsu \& J. Seelig, unpublished results.)

ted glycerols, the glycerol backbone of the various phospholipids as well as the head groups of phosphatidylglycerol and cardiolipin are selectively labelled (H. U. Gally, G. Pluschke, P. Overath \& J. Seelig, unpublished results). Well-resolved ${ }^{2} \mathrm{H}-\mathrm{nmr}$ spectra have been obtained from the various segments, opening the way for a comprehensive headgroup study of an intact biological membrane. It can therefore be hoped that the application of ${ }^{2} \mathrm{H}$ - and ${ }^{31} \mathrm{P}-\mathrm{nmr}$ methods to the polar head-group region will become equally fruitful and revealing as it already has been for the study of the hydrophobic part of the bilayer membrane.

\section{ACKNOWLEDGEMENTS}

This work was supported by the Swiss National Science Foundation grant no. 3.409.79. 


\section{REFERENCES}

ACHLAMA, A. \& ZUR, Y. (1979). The electric field gradient tensor of the olefinic deuterons of potassium hydrogen maleate. F. Magn. Reson. 36, 249-258.

Bцоом, M. (1979). Squishy proteins in fluid membranes. Can. F. Phys. 57, 2227-2230.

Brown, M. F. \& SEELIG, J. (I977). Ion induced changes in the head-group conformation of lecithin bilayers. Nature, Lond. 269, 72 I-723.

Brown, M. F., \& SEELIG, J. (1978). Influence of cholesterol on the polar region of phosphatidylcholine and phosphatidylethanolamine bilayers. Biochemistry, N.Y. 17, $3^{81-384 . ~}$

Brown, M. F., Seelig, J. \& HÄberlen, U. (1979). Structural dynamics in phospholipid bilayers from deuterium spin lattice relaxation time measurements. F. Chem. Phys. 70, 5045-5053.

Browning, J. L. \& Seelig, J. (I980). Bilayers of phosphatidylserine: a deuterium and phosphorus NMR study. Biochemistry, N.Y.19, 12621270.

BüLDT, G. \& SeELIG, J. (I980). The conformation of phosphatidylethanolamine in the gel phase as seen by neutron diffraction. Biochemistry, $N, Y$. in press.

Büldt, G., Gally, H. U., Seelig, A., Seelig, J. \& Zaccai, G. (1978). Neutron diffraction studies on selectively deuterated phospholipid bilayers. Nature, Lond. 271, 182-184.

Büldt, G., Gally, H. U., SeElig, J. \& Zaccai, G. (1979). Neutron diffraction studies on phosphatidylcholine model membranes. I. Head-group conformation. f. molec. Biol. 134, 673-691.

BurnetT, L. J. \& Muller, B. H. (I97I). Deuteron quadrupole coupling constants in three solid deuterated paraffin hydrocarbons: $\mathrm{C}_{2} \mathrm{D}_{6}, \mathrm{C}_{4} \mathrm{D}_{\mathbf{1 0}}$, $\mathrm{C}_{6} \mathrm{D}_{14}$. F. Chem. Phys. 55, 5829-583r.

Cain, J., Santillan, G. \& Blasie, J. K. (1972). Molecular motion in membranes as indicated by X-ray diffraction. In Membrane Research (ed. F. Fox), pp. 3-14. New York, N.Y.: Academic Press.

Chapman, D. (1975). Phase transitions and fluidity characteristics of lipids and cell membranes. $Q$. Rev. Biophys. 8, I 85-235.

Chapman, D., Cornell, B. A., Eliasz, A. W. \& Perry, A. (1977). Interactions of helical polypeptide segments which span the hydrocarbon region of lipid bilayers. $\mathcal{F}$. molec. Biol. 113, 517-538.

Chapman, D., Gomez-Fernandez, J. C. \& Goni, F. M. (1979). Intrinsic protein-lipid interactions. FEBS Lett. 98, 211 -223.

ChERRY, R. J. (1979). Rotational and lateral diffusion of membrane proteins. Biochim. biophys. Acta 559, 289-327.

Cherry, R. J., Mueller, U. \& SChNeider, G. (1977). Rotational diffusion of bacteriorhodopsin in lipid membranes. FEBS Lett. 80, 465-468.

Cullis, P. R. \& De KruijfF, B. (1976). ${ }^{31} \mathrm{P} \mathrm{nmr}$ studies of unsonicated aqueous dispersions of neutral and acidic phospholipids. Effects of 
phase transitions, $\mathrm{pH}$ and divalent cations on the motion of the phosphate region of the polar head group. Biochim. biophys. Acta 436, 523-540.

Cullis, P. R. \& De KruijfF, B. (1978). The polymorphic phase behaviour of phosphatidylethanolamines of natural and synthetic origin. Biochim. biophys. Acta 513, 31-42.

Cullis, P. R. \& De KruijfF, B. (1979). Lipid polymorphism and the functional roles of lipids in biological membranes. Biochim. biophys. Acta 559, 399-420.

Curatolo, W., Sakura, J. D., Small, D. M. \& Shipley, G. G. (1977). Protein-lipid interactions: recombinants of the proteolipid apoprotein of myelin with dimyristoyl lecithin. Biochemistry, N.Y. 16, 2313-2319.

Davis, J. H. (1979). Deuterium magnetic resonance study of the gel and liquid crystalline phases of dipalmitoyl phosphatidylcholine. Biophys. $\mathcal{F}$. 27, 339-358.

Davis, J. H., JeFFrey, K. R. \& Bloom, M. (1978). Spin-lattice relaxation as a function of chain position in perdeuterated potassium palmitate. $\mathcal{F}$. Magn. Res. 29, 19I-199.

Davis, J. H., Jeffrey, K. R., Bloom, M., Valic, M. I. \& Higgs, T. P. (1976). Quadrupolar echo deuteron magnetic resonance spectroscopy in ordered hydrocarbon chains. Chem. Phys. Lett. 42, 390-394.

Davis, J. H., Nichol, C. P., WeEks, G. \& Bloom, M. (I979). Study of the cytoplasmic and outer membranes of Escherichia coli by deuterium magnetic resonance. Biochemistry, N.Y. 18, 2103-2112.

Davoust, J., Bienvenue, A., Fellmann, P. \& Deveaux, P. F. (i980). Boundary lipids and protein mobility in rhodopsin-phosphatidylcholine vesicles. Effect of lipid phase transition. Biochim. biophys. Acta 596, 28-42.

Dix, J. A., Kivelson, D. \& Diamond, J. M. (I978). Molecular motion of small nonelectrolyte molecules in lecithin bilayers. F. Membrane Biol. 4o, 315-342.

ENGELMAN, D. M. (1971). Lipid bilayer structure in the membrane of Mycoplasma laidlawii. f. molec. Biol. 58, $153-165$.

FloRY, P. J. (1969). Statistical Mechanics of Chain Molecules. New York, N.Y.: Interscience.

FurThmayr, H. (1977). Structural analysis of a membrane glycoprotein: Glycophorin A. F. Supramol. Struct. 7, 121-134.

Gaber, B. P. \& Peticolas, W. L. (1977). On the quantitative interpretation of biomembrane structure by Raman spectroscopy. Biochim. biophys. Acta 465, 260-274.

Gally, H. U., Niederberger, W. \& Seelig, J. (1975). Conformation and motion of the choline head group in bilayers of dipalmitoyl-3-snphosphatidylcholine. Biochemistry N.Y. 14, 3647-3652.

Gally, H. U., Seelig, A. \& Seelig, J. (1976). Cholesterol induced rod-like motion of fatty acyl chains in lipid bilayers. A deuterium magnetic resonance study. Hoppe Seyler's Z. Physiol. Chem. 357, 1447-I450.

Gally, H. U., Pluschke, G., Overath, P. \& Seelig, J. (I979). Structure of Escherichia coli membranes. Phospholipid conformation in model 
membranes and cells as studied by deuterium magnetic resonance. Biochemistry, N.Y. 18, 5605-5610.

Gally, H. U., Pluschke, G., Overath, P. \& Seelig, J. (ig80). Structure of Escherichia coli membranes. Fatty acyl chain order parameters of inner and outer membrane and derived liposomes. Biochemistry, N.Y. 19, $1638-1643$.

Gomez-Fernandez, J. C., Goni, F. M., Bach, D., Restall, C. \& Chapman, D. (1979). Protein-lipid interactions. A study of $\left(\mathrm{Ca}^{2+}, \mathrm{Mg}^{2+}\right)$ ATPase reconstituted with synthetic phospholipids. FEBS Lett. 98, 224-228.

GRIFrin, R. G. (1976). Observation of the effect of water on the ${ }^{31} \mathrm{P}$ nuclear magnetic resonance spectra of dipalmitoyllecithin. F. Am. Chem. Soc. 98, $85 I-853$.

Gruen, D. W. R. (1980). A statistical-mechanical model of the lipid bilayer above its phase transition. Biochim. biophys. Acta 595, 16 $6 \mathrm{I}-\mathrm{I} 83$.

Haberkorn, R. A., Griffin, R. G., Meadows, M. D., \& Oldfield, E. (1977). Deuterium nuclear magnetic resonance investigation of the dipalmitoyl lecithin-cholesterol water system. F. Am. Chem. Soc. 99, 7353-7355.

HARE, F. \& LusSAN, C. (1977). Variations in microviscosity values induced by different rotational behaviour of fluorescent probes in some aliphatic environments. Biochim. biophys. Acta 467, 262-272.

Hauser, H. \& Phillips, M. C. (1979). Interactions of the polar groups of phospholipid bilayer membranes. Progr. Surf. \& Membrane Sci. 13, 297-4I3.

Hauser, H., Guyer, W., Pascher, I., Skrabal, P. \& Sundell, S. (1980). Polar group conformation of phosphatidylcholine. Effect of solvent and aggregation. Biochemistry, N.Y. 19, 366-373.

Herzfeld, J., Griffin, R. G. \& Haberkorn, R. A. (1978). Phosphorus-3i chemical shift tensors in barium diethyl phosphate and urea-phosphoric acid: model compounds for phospholipid head-group studies. Biochemistry, N.Y. $17,271 \mathrm{I}-2718$.

Hesketh, T. R., Smith, G. A., Houslay, M. D., McGill, K. A., Birdsall, N. J. M., Metcalfe, J. \& Warren, G. B. (1976). Annular lipids determine the ATPase activity of a Calcium transport protein complexed with dipalmitoyllecithin. Biochemistry, N.Y. 15, 4145-41 5 I.

HeYN, M. P. (1979). Determination of lipid order parameters and rotational correlation times from fluorescence depolarization experiments. FEBS Lett. 108, 359-364.

Hitchcock, P. B., Mason, R., Thomas, K. M. \& Shipley, G. G. (1974). Structural chemistry of 1,2-dilauroyl-DL-phosphatidyl-ethanolamine: Molecular conformation and intermolecular packing of phospholipids. Proc. natn. Acad. Sci. U.S.A. 7x, 3036-3040.

JACOBS, R. \& OLDFIELD, E. (1979). Deuterium nuclear magnetic resonance investigation of dimyristoyllecithin-dipalmitoyllecithin and dimyristoyllecithin-cholesterol mixtures. Biochemistry, N.Y. 18, 3280-3285.

JäHNIG, F. (1979). Structural order of lipids and proteins in membranes. Evaluation of fluorescence anisotropy data. Proc. natn. Acad. Sci. U.S.A. 76, 636r-6365. 
Jost, P. C. \& Griffith, O. H. (1980). The lipid-protein interface in biological membranes. Ann. NY. Acad. Sci. (in the Press).

Jost, P. C., Griffith, O. H., Capaldi, R. A. \& Vanderkooi, G. (I973). Evidence for boundary lipids in membranes. Proc. natn. Acad. Sci. U.S.A. 70, $480-484$.

Kang, S. Y., Gutowsky, H. S. \& OldField, E. (1979). Spectroscopic studies of specifically deuterium labelled membrane systems. Nuclear magnetic resonance investigation of protein-lipid interactions in Escherichia coli membranes. Biochemistry, N.Y. 18, 3268-3272.

Kang, S. Y., Gutowsky, H. S., Hshung, J. C., Jacobs, R., King, T. E., RICE, D. \& OLDFIELD, E. (I979). Nuclear magnetic resonance investigation of the cytochrome oxidase-phospholipid interaction. A new model for boundary lipid. Biochemistry N.Y. 18, 3257-3267.

KOHLER, S. J. \& KLEIN, M. P. (1976). ${ }^{\text {s1 }}$ P chemical shielding tensors of phosphorylethanolamine, lecithin and related compounds: Application to head-group motion in membranes. Biochemistry, N.Y. 15, 967-973.

Kowalewski, J., Lindblom, T., Vestin, R. \& Drakenberg, T. (i976). Deuteron magnetic resonance of monodeuteroethene: Isotropic and anisotropic phase spectra. Molec. Phys. 3r, I669-1676.

Lee, A. G., Birdsall, N. J. M., Metcalf, J. C., Warren, G. B. \& Roberts, G. C. K. (1976). A determination of the mobility gradient in lipid bilayers by ${ }^{13} \mathrm{C}$ nuclear magnetic resonance. Proc. $R$. Soc. B. 193, 253-274.

Luzzati, V. (1968). X-ray diffraction studies of lipid-water systems. In Biological Membranes (ed. D. Chapman), pp. 71-123. New York, N.Y.: Academic Press.

Luzzati, V. \& Husson, F. ( 1962 ). The structure of the liquid-crystalline phases of lipid-water systems. $\mathcal{F}$. Cell. Biol. 12, 207-219.

Mabrey, S., Mateo, P. L., \& Sturtevant, J. M. (1978). High-sensitivity scanning calorimetric study of mixtures of cholesterol with dimyristoyland dipalmitoyl phosphatidylcholines. Biochemistry, N.Y. 17, 2464-2468.

Mantsch, H. H., SaIto, H. \& SMIth, I. C. P. (1977). Deuterium magnetic resonance. Applications in Chemistry, physics and biology. Progr. NMR Spectroscopy r I, $21 \mathrm{I}-272$.

MarčElJA, S. (1974). Chain ordering in liquid crystals. II. Structure of bilayer membranes. Biochim. biophys. Acta 367, 165-176.

MeIrovitch, E. \& FreEd, J. H. (1979). Slow motional lineshapes for very anistropic diffusion: $\mathrm{I}=\mathrm{I}$ nuclei. Chem. Phys. Lett. 64, 3 I I-3 I6.

Mely, B., Charvolin, J. \& Keller, P. (1975). Disorder of lipid chains as a function of their lateral packing in lyotropic liquid crystals. Chem. Phys. Lipids I5, I61-173.

Mombers, C., Verkleij, A. J., De Gier, J. \& Van Deenen, L. L. M. (1979). The interaction of spectrin-actin and synthetic phospholipids. II. The interaction with phosphatidylserine. Biochim. biophys. Acta 551, 271-281.

Nichol, C. P., Davis, J. H., Weeks, G. \& Bloom, M. (I980). Quantitative study of the fluidity of Escherichia coli membranes using deuterium magnetic resonance. Biochemistry, N.Y. 19, 45 I-457. 
Niederberger, W., \& Seelig, J. (1976). Phosphorus-31 chemicals shift anisotropy in unsonicated phospholipid bilayers. F. Am. Chem. Soc. 98, 3704-3706.

Oldfield, E., Meadows, M., Rice, D. \& Jacobs, R. (1978a). Spectroscopic studies of specifically deuterium labelled membrane systems. Nuclear magnetic resonance investigation of the effects of cholesterol in model systems. Biochemistry, N.Y. 17, 2727-2740.

Oldfield, E., Gilmore, R., Glaser, M., Gutowsky, H. S., Hshung, J. C., Kang, S. Y., Tsoo E. King, Meadows, M. \& Rice, D. (1978b). Deuterium nuclear magnetic resonance investigation of the effects of proteins and polypeptides on hydrocarbon chain order in model membrane systems. Proc. natn. Acad. Sci. U.S.A. 75, 4657-466o.

Oldfield, E., Meadows, M. \& Glaser, M. (1976). Deuterium magnetic resonance spectroscopy of isotopically labelled mammalian cells. $\mathcal{f}$. biol. Chem. 251, 6147-6149.

Pearson, R. H. \& Pascher, I. (1979). The molecular structure of lecithin dihydrate. Nature, Lond. 281, 499-50I.

Phillips, M. C., Williams, R. M. \& Chapman, D. (1969). On the nature of hydrocarbon chain motions in lipid liquid crystals. Chem. Phys. Lipids 3 , 234-244.

PINK, D. A. \& Zuckermann, M. J. (1980). Lipid chain order in Acholeplasma laidlawii membranes. What does ${ }^{2} \mathrm{H} \mathrm{nmr}$ tell us? FEBS Lett. xo9, 5-8.

Rance, N., Jefrrey, K. R., Tulloch, A. P., Butler, K. W. \& Smith, I. C. P. (1980). Orientational order of unsaturated phospholipids in the membranes of Acholeplasma laidlawii as observed by deuterium nmr. Biochim. biophys. Acta (in the Press).

Rand, R. P., Tinker, D. O. \& Fast, P. G. (1971). Polymorphism of phosphatidylethanolamines from two natural sources. Chem. Phys. Lipids 6, 333-342.

Rice, D. M., Meadows, M. D., Scheinman, A. O., Goni, F. M., GomezFernandez, J. C., Moscarello, M. A., Chapman, D. \& Oldfield, E. (1979). Protein-lipid interactions. A nuclear magnetic resonance study of sarcoplasmic reticulum $\mathrm{Ca}^{2+}, \mathrm{Mg}^{2+}$-ATPase, lipophilin, and proteolipid apoprotein-lecithin systems and a comparison with the effects of cholesterol. Biochemistry, N.Y. 18, 5893-5903.

SANDERMANN, H. (1978). Regulation of membrane enzymes by lipids. Biochim. biophys. Acta 5r5, 209-237.

SCHINDLER, H. \& SEelig, J. (I975). Deuterium order parameters in relation to thermodynamic properties of a phospholipid bilayer. A statistical mechanical interpretation. Biochemistry, N.Y. 14, 2283-2287.

Seelig, A. \& Seelig, J. (1974). The dynamic structure of fatty acyl chains in a phospholipid bilayer measured by deuterium magnetic resonance. Biochemistry, N.Y. 13, 4839-4845.

Seelig, A. \& SeELig, J. (I975). Bilayers of dipalmitoyl-3-sn-phosphatidylcholine. Conformational differences between the fatty acyl chains. Biochim. biophys. Acta 406, 1-5. 
Serlig, A. \& Seelig, J. (1977). Effect of a single cis-double bond on the structure of a phospholipid bilayer. Biochemistry, N.Y. 16, 45-50.

SeElig, A. \& SeElig, J. (1978). Lipid-protein interaction in reconstituted cytochrome $c$ oxidase phospholipid membranes. Hoppe-Seyler's $Z$. Physiol. Chem. 359, 1747-1 $75^{6}$.

SEeLIG, J. (I977). Deuterium magnetic resonance: theory and application to lipid membranes. $Q$. Rev. Biophys. 10, 353-418.

SeElig, J. (1978). Phosphorus-3I nuclear magnetic resonance and the headgroup structure of phospholipids in membranes. Biochim. biophys. Acta 505, I05-141.

SeElig, J. \& Browning, J. L. (1978). General features of phospholipid conformation in membranes. FEBS Lett. 92, $4 \mathrm{I}-44$.

Seelig, J., Dijkman, R. \& De HaAs, G. H. (1980). Thermodynamic and conformational studies on 2-sn-phosphatidylcholines in monolayers and bilayers. Biochemistry, N.Y. 19, 221 5-2219.

SEELIG, J. \& GALly, H. U. (I976). Investigation of phosphatidylethanolamine bilayers by deuterium and phosphorus- 3 I nuclear magnetic resonance. Biochemistry, N.Y. 15, 5199-5204.

Seelig, J., Gally, H. U. \& Wohlgemuth, R. (1977). Orientation and flexibility of the choline head group in lecithin bilayers. Biochim. biophys. Acta 467, I09-II9.

SeElig, J. \& Limacher, H. (I974). Lipid molecules in lyotropic liquid crystals with cylindrical structure. (A spin label study.) Mol. Cryst. Liquid Cryst. 25, I05-I I 2.

Seelig, J. \& Niederberger, W. (1974). Two pictures of a lipid bilayer. A comparison between deuterium label and spin experiments. Biochemistry, $N . Y ., 13,15^{8} 5^{-1} 5^{88}$.

Seelig, J., Tamm, L., Fleischer, S. \& Hymel, L. (1980). Deuterium and phosphorus $\mathrm{nmr}$ and fluorescence depolarization studies of functional reconstituted sarcoplasmic reticulum membrane vesicles. (Manuscript in preparation.)

SeElig, J. \& WaESEPE-SarČevic̀, N. (1978). Molecular order in cis and trans unsaturated phospholipid bilayers. Biochemistry, N.Y. 17, 3310-3315.

SHEPHERD, J. C. W. \& BüLDT, G. (1978). Zwitterionic dipoles as a dielectric probe for investigating head-group mobility in phospholipid membranes. Biochim. biophys. Acta 514, 83-94.

SHIPLEY, G. (1973). Recent X-ray diffraction studies of biological membranes and membrane components. In Biological Membranes, Vol. 2, (ed. D. Chapman and D. F. H. Wallach), pp. I-89. New York, N.Y.: Academic Press.

Singer, S. J. (1971). The molecular organization of biological membranes. In Structure and Function of Biological Membranes (ed. I. Rothfield), pp. 146-222. New York, N.Y.: Academic Press.

Skarjune, R. \& Oldfield, E. (ig79a). Physical studies of cell surface and cell membrane structure. Deuterium nuclear magnetic resonance investigation of deuterium-labelled $N$-hexadecanoyl-galactosylceramides (cerebrosides). Biochim. biophys. Acta 556, 208-2 18. 
Skarjune, R. \& Oldfield, E. (1979b). Physical studies of cell surface and cell membrane structure. Determination of phospholipid head-group organization by deuterium and phosphorus nuclear magnetic resonance spectroscopy. Biochemistry, N.Y. 18, 5903-5909.

Smith, I. C. P., Butler, K. W., Tulloch, A. P., Davis, J. H. \& Bloom, M. (1979). The properties of gel state lipid membranes of Acholeplasma laidlawii as observed by deuterium nuclear magnetic resonance. FEBS Lett. roo, $57-6$ r.

Stockton, G. W. \& SмIт,, I. C. P. (1976). A deuterium magnetic resonance study of the condensing effect of cholesterol on egg phosphatidylcholine bilayer membranes. I. Perdeuterated fatty acid probes. Chem. Phys. Lipids $\mathbf{1 7}, 25 \mathrm{I}-263$.

Stockton, G. W., Johnson, K. G., Butler, K., Tulloch, A. P., Boulanger, Y., Smith, I. C. P., Davis, J. H. \& Bloom, M. (I977). Deuterium NMR study of lipid organisation in Acholeplasma laidlawii membranes. Nature 269, 268-268.

Stockton, G. W., Polnaszek, C. F., Tulloch, A. P., Hasan, F. \& Smith, I. C. P. (1976). Molecular motion and order in single-bilayer vesicles and multilamellar dispersions of egg lecithin and lecithin cholesterol mixtures. A deuterium nuclear magnetic resonance study of specificallylabelled lipids. Biochemistry, N.Y. 15, 954-966.

Stoffel, W., ZierenberG, O. \& ScheEfers, H. (I977). Reconstitutiou of $\mathrm{Ca}^{2+}$ ATPase of sarcoplasmic reticulum with ${ }^{13} \mathrm{C}$-labelled lipids. HoppeSeyler's Z. physiol. Chem. 358, 865-882.

Tardieu, A., Luzzati, V. \& Reman, F. C. (1973). Structure and polymorphism of the hydrocarbon chains of lipids: A study of lecithin-water phases. 7. molec. Biol. 75, $7 \mathrm{I} I-733$.

TRÄUBLE, H. (197r). The movement of molecules across lipid membranes. A molecular theory. F. Membrane Biol. 4, 193-208.

Van Deenen, L. L. M. (1965). Phospholipids and biomembranes. Prog. Chem. Fats 8, I-127.

Van Zoelen, E. J. J., Van Dijck, P. W. M., De KruijfF, B., Verkleij, A. J. \& VAN DEENEN, L. L. M. (1978). Effect of glycophorin incorporation on the physico-chemical properties of phospholipid bilayers. Biochim. biophys. Acta 514, 9-24.

WoHLgEMuTh, R., WAESPE-SARČEvič, N. \& SEELIG, J. (1980). Bilayers of phosphatidylglycerol. A deuterium and phosphorus $\mathrm{nmr}$ study of the head-group region. Biochemistry, N.Y. in press.

WORCESTER, D. L. (1976). Neutron beam studies of biological membranes and membrane components. In Biological Membranes, vol. 3. (ed. D. Chapman and D. F. H. Wallach), pp. I-44. London: Academic Press.

Worcester, D. L. \& Franks, N. P. (1976). Neutron diffraction analysis of hydrated egg lecithin and cholesterol bilayers. F. molec. Biol. roo, 359-378.

Zaccai, G., Büldt, G., Seelig, A. \& Seelig, J. (1979). Neutron diffraction studies on phosphatidylcholine model membranes. II. Chain conformation and segmental disorder. F. molec. Biol. 134, 693-706. 